\title{
Peroxisome biogenesis deficiency attenuates the BDNF-TrkB pathway-mediated development of the cerebellum
}

\author{
Yuichi Abe ${ }^{1}$, Masanori Honsho ${ }^{1}$, Ryota Itoh², Ryoko Kawaguchi², Masashi Fujitani ${ }^{3}$, Kazushirou Fujiwara ${ }^{2}$, \\ Masaaki Hirokane ${ }^{2}$, Takashi Matsuzaki ${ }^{2}$, Keiko Nakayama ${ }^{4,5}$, Ryohei Ohgi ${ }^{2}$, Toshihiro Marutani ${ }^{2}$, Keiichi I Nakayama ${ }^{4}$, \\ Toshihide Yamashita ${ }^{3,6}$, Yukio Fujiki ${ }^{1}$ (]
}

\begin{abstract}
Peroxisome biogenesis disorders (PBDs) manifest as neurological deficits in the central nervous system, including neuronal migration defects and abnormal cerebellum development. However, the mechanisms underlying pathogenesis remain enigmatic. Here, to investigate how peroxisome deficiency causes neurological defects of PBDs, we established a new PBD model mouse defective in peroxisome assembly factor Pex14p, termed Pex14 ${ }^{\Delta C / \Delta C}$ mouse. Pex14 ${ }^{\Delta C / \Delta C}$ mouse manifests a severe symptom such as disorganization of cortical laminar structure and dies shortly after birth, although peroxisomal biogenesis and metabolism are partially defective. The Pex $14^{\Delta C / \Delta C}$ mouse also shows malformation of the cerebellum including the impaired dendritic development of Purkinje cells. Moreover, extracellular signalregulated kinase and AKT signaling are attenuated in this mutant mouse by an elevated level of brain-derived neurotrophic factor (BDNF) together with the enhanced expression of TrkB-T1, a dominant-negative isoform of the BDNF receptor. Our results suggest that dysregulation of the BDNF-TrkB pathway, an essential signaling for cerebellar morphogenesis, gives rise to the pathogenesis of the cerebellum in PBDs.
\end{abstract}

DOI 10.26508/Isa.201800062 | Received 2 April 2018 | Revised 8 November 2018 | Accepted 8 November 2018 | Published online 3 December 2018

\section{Introduction}

The peroxisome serves as a platform for various catabolic and anabolic reactions, such as $\beta$-oxidation of very long-chain fatty acids (VLCFAs), degradation of hydrogen peroxide, and plasmalogen biogenesis (Wanders \& Waterham, 2006). The physiological consequence of peroxisomal function is highlighted by the pathogenesis of peroxisome biogenesis disorders (PBDs), autosomal recessive diseases manifesting as progressive disorders of the central nervous system (CNS) (Weller et al, 2003; Steinberg et al, 2006). PBDs, including Zellweger spectrum disorders (ZSDs), rhizomelic chondrodysplasia punctata type 1 (RCDP1) (Braverman et al, 1997; Motley et al, 1997; Purdue et al, 1997), and RCDP5 (Barøy et al, 2015), are caused by mutations of PEX genes encoding peroxins required for peroxisome assembly (Waterham \& Ebberink, 2012; Fujiki et al, 2014; Fujiki, 2016). The primary defects of RCDP1 and RCDP5 are the loss of PEX7 and the long isoform of PEX5, respectively, whereas mutations in any of the other PEX genes give rise to the ZSD. ZSDs, accounting for about $80 \%$ of the PBD patients (Weller et al, 2003), are classified into three groups according to their clinical severity: Zellweger syndrome (ZS), neonatal adrenoleukodystrophy (NALD), and infantile Refsum disease (IRD) (Steinberg et al, 2006). Patients with ZS, the most severe ZSDS, generally die before reaching the age of $1 \mathrm{yr}$. The CNS pathological features of patients with ZS include migration defects in cortical neurons, abnormal dendritic arborization of Purkinje cells, and dysplastic alterations of inferior olivary nuclei (ION) (Volpe \& Adams, 1972; de León et al, 1977; Evrard et al, 1978; Steinberg et al, 2006). The biochemical abnormalities, including marked reduction of plasmalogens, accumulation of VLCFAs, and reduction in the level of docosahexaenoic acid (DHA) (Weller et al, 2003), are thought to be relevant to the manifestations of malformations in the CNS. However, the pathogenic mechanisms of PBDs are largely unknown.

To study the pathogenesis of ZSDs, mice with generalized inactivation of the Pex genes Pex2, Pex5, and Pex13 have been established (Baes et al, 1997; Faust \& Hatten, 1997; Maxwell et al, 2003). The deletion of individual Pex genes causes the complete deficiency of peroxisomal protein import and abnormal

\footnotetext{
'Division of Organelle Homeostasis, Medical Institute of Bioregulation, Kyushu University, Fukuoka, Japan ${ }^{2}$ Graduate School of Systems Life Sciences and Department of Biology, Faculty of Sciences, Kyushu University Graduate School, Fukuoka, Japan ${ }^{3}$ Department of Molecular Neuroscience, Graduate School of Medicine, Osaka University, Osaka, Japan ${ }^{4}$ Department of Molecular and Cellular Biology, Medical Institute of Bioregulation, Kyushu University, Fukuoka, Japan ${ }^{5}$ Division of Cell Proliferation, Tohoku University Graduate School of Medicine, Sendai, Japan ${ }^{6}$ Core Research for Evolutional Science and Technology, Japan Science and Technology Agency, Tokyo, Japan
} 
morphology of the CNS (Baes et al, 1997; Faust \& Hatten, 1997; Faust, 2003; Maxwell et al, 2003), as reported in patients with ZS (Volpe \& Adams, 1972; Evrard et al, 1978; Powers \& Moser, 1998). Moreover, the mutation of Pex genes in the CNS results in dysfunction of peroxisomes in neurons, oligodendrocytes, and astrocytes, giving rise to abnormal development and aberrant brain morphology (Krysko et al, 2007; Müller et al, 2011), as observed in Pex-null mice (Baes et al, 1997; Faust \& Hatten, 1997; Faust, 2003; Maxwell et al, 2003). However, mice with neural cell type-selective conditional knockout of Pex genes do not show abnormal CNS development (Kassmann et al, 2007; Bottelbergs et al, 2010). Normal development in these mice has been suggested to be due to the shuttling of peroxisomal metabolites and supportive effects among different brain cell types (Bottelbergs et al, 2010). Therefore, investigation of cell-cell interaction between neuronal cells might serve as a potential clue to reveal the pathological mechanisms underlying the abnormal development of neuronal cells. In the present study, as a step toward uncovering pathological mechanisms underlying ZSDs, we established a new ZSD model mouse, defective in Pex14. The Pex14-defective mouse manifests severe symptoms in CNS and growth retardations, while the peroxisome biogenesis and metabolism are partially defective. Moreover, the up-regulation of brain-derived neurotrophic factor (BDNF) was observed in the cerebellum of a Pex14-defective mouse, manifesting the dysmorphogenesis of Purkinje cells. Taken together, our results suggest for the first time the pathogenesis of abnormal cerebellar development in ZSDs.

\section{Results}

\section{Generation of a Pex14-defective mouse}

To investigate how peroxisome deficiency causes malformation of CNS in patients with ZSDs, we established a Pex14 mutant mouse with deletion of the $\mathrm{C}$-terminal half part of Pex14p by eliminating exons 6-8 from the Pex14 gene on a C57BL/ 6 background, termed Pex $14^{\Delta C / \Delta C}$ mouse (Fig $1 A$ and $B$ ). This deletion of exons 6-8 induced a frameshift of the amino acid at position 129 and generated premature termination at position 164 (Fig 1C, middle), giving rise to the C-terminal-truncated mutant of Pex14p similar to that found in a patient with ZS (Shimozawa et al, 2004) (Pex14p-Q185X, Fig 1C, bottom). The patient with Pex14p-Q185X mutation manifested severe CNS defects, such as hypotonia and psychomotor retardation, and died at the age of $10 \mathrm{~d}$ (Shimozawa et al, 2004). Nevertheless, skin fibroblasts from the patient showed partial defects in peroxisomal biogenesis and metabolism (Fig S1).

Pex $14^{\Delta C / \Delta C}$ pups were generated by breeding heterozygous Pex14 mutants, and the expected Mendelian ratio of 22 wild-type mice (Pex14 $\left.4^{+/}, 24 \%\right), 48$ heterozygous mice (Pex14 $\left.{ }^{+/ \Delta C}, 53 \%\right)$, and 21 homozygous mutant mice (Pex14 ${ }^{\Delta C / \Delta C}, 23 \%$ ) was obtained (Fig 1E). However, homozygous neonates died shortly after birth or within several days (data not shown). Neonates with the mutation were smaller in body size than those of wild-type mice at birth (Fig 1D), and body weights of neonatal Pex14 ${ }^{\Delta C / \Delta C}$ mice were indeed lower at P0.5 (Fig 1E). Cresyl violet staining of coronal sections revealed that neurons migrating to the cortex accumulated in the intermediate zone at the medial region (Fig 1F) as previously reported in other Pexknockout mice (Baes et al, 1997; Faust \& Hatten, 1997; Janssen et al, 2003; Maxwell et al, 2003). In the cortical layer, cells with elongated shapes such as pyramidal cells are normally localized in cortical layer $\mathrm{V}$ of the wild-type mouse (Fig $1 \mathrm{G}$, left panel). By contrast, in the brain of the Pex $14^{\Delta C / \Delta C}$ mouse, more darkly stained cells with rounder shapes were accumulated in layer $V$ and the boundary was obscured between layers IV and V (Fig 1G, right panel).

Next, we analyzed peroxisomal biogenesis in the Pex $14^{\Delta C / \Delta C}$ mouse brain. Expression and peroxisomal localization of Pex14p truncated at the $\mathrm{C}$-terminal portion were detected with an antibody to the N-terminal region of Pex14p (Pex14pN) (Itoh \& Fujiki, 2006) (Fig 2D and E), but not with an antibody against the C-terminal portion of Pex14p (Pex14pC) in Pex14 ${ }^{\Delta C / \Delta C}$ mouse brain (Fig 2A, B, D, and E). Catalase was diffused throughout the cytosol (Fig 2C) and import of peroxisomal targeting signal 1 (PTS1) and PTS2 proteins was partially defective in the Pex $14^{\Delta C / \Delta C}$ mouse (Fig 2A, B, and E) as shown by the reduced level of intraperoxisomal conversion of the acyl-CoA oxidase 1 (AOX) A-chain to B-chain (Fig 2E) and C-chain (not shown) (Miyazawa et al, 1989) and the fluorescence intensity for alkyldihydroxyacetonephosphate synthase (ADAPS) (Fig 2B). Peroxisomal membranes were discernible by staining with an antibody to PMP70 and appeared similar to those observed in the wild-type mouse brain (Fig 2C). Taken together, these results indicated that the $\mathrm{C}$-terminal deletion of Pex14p gave rise to a partial defect in peroxisomal matrix protein import and wholly impaired catalase import.

We examined phospholipid metabolism in the mouse brain by liquid chromatography coupled with tandem mass spectrometry (LC-MS/MS) analysis. The plasmenylethanolamine (PlsEtn) level in the Pex14 ${ }^{\Delta C / \Delta C}$ mouse brain was reduced to nearly $50 \%$ of that in the wild-type mouse (Fig 2F). Typical metabolic abnormalities in peroxisome biogenesis deficiency, including accumulation of VLCFAcontaining phosphatidylcholine (VLCPC; Fig 2G) and decrease in DHA-containing phospholipids (DHA-PLs; Fig 2H), were also evident in the Pex $14^{\Delta C / \Delta C}$ mouse brain. However, these metabolic aberrations in $\operatorname{Pex} 14^{\Delta C / \Delta C}$ mice were milder than those in other Pexknockout mice, such as 100-fold reduction of PlsEtn and sixfold or more accumulation of VLCFAs (Baes et al, 1997; Faust et al, 2001; Maxwell et al, 2003). Therefore, partial defect of peroxisomal protein import causes the mild metabolic abnormalities in the Pex $14^{\Delta C / \Delta C}$ mice. The heterozygous Pex $14^{+/ \Delta C}$ mouse showed no anomalies in growth (Fig 1D and E), AOx conversion (Fig 2E), and peroxisomal lipid metabolism (Fig 2F-H), whereas Pex14p was markedly reduced (Fig 2E).

Collectively, these data demonstrated that mild defects in peroxisome biogenesis and metabolism are sufficient to manifest as the symptoms of ZS. Thus, we concluded that the Pex $14^{\Delta C / \Delta C}$ mouse was a good model of ZS. However, morphological abnormalities of the CNS other than migration defect of cortical neurons (Fig $1 F$ and G and S2), such as cerebellar malformation in the patients with ZS (Volpe \& Adams, 1972; de León et al, 1977; Evrard et al, 1978), were not evident in Pex14 ${ }^{\Delta C / \Delta C}$ mouse (data not shown). Because the cerebellum undergoes dramatic developmental change during the first three postnatal weeks in mice, it was difficult to verify the dysmorphology of the cerebellum in neonatal $\operatorname{Pex} 14^{\Delta C / \Delta C}$ mice, which died shortly after birth. 
Life Science Alliance

A

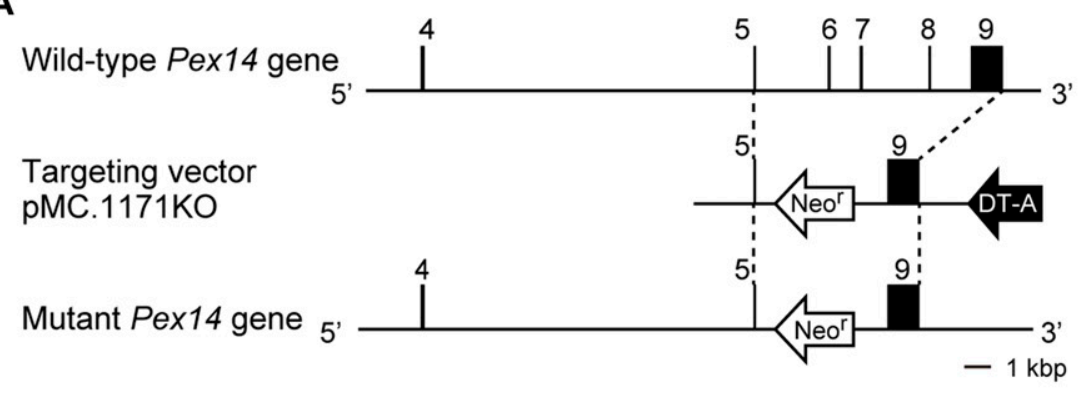

B

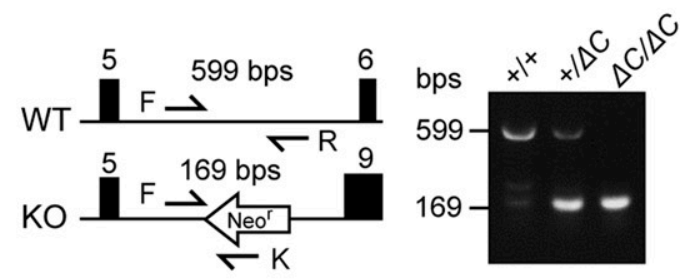

C

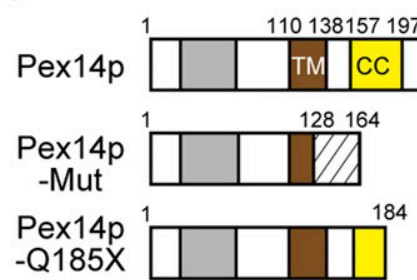

D

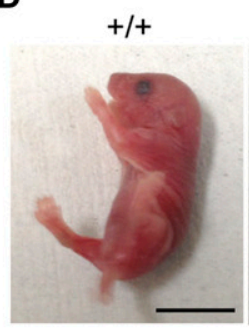

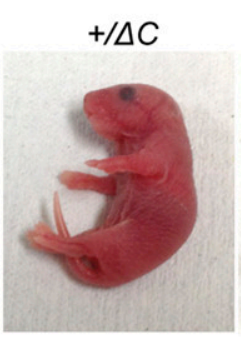

G

\section{F $<$ P0.5 Cortex $>$}

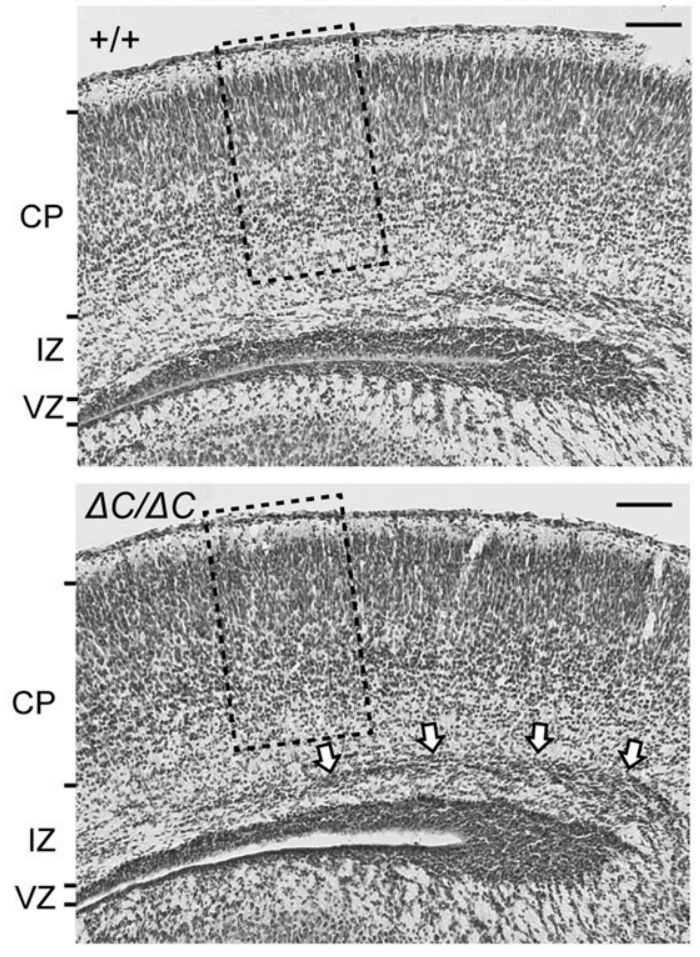

$<$ P0.5 Cortex >

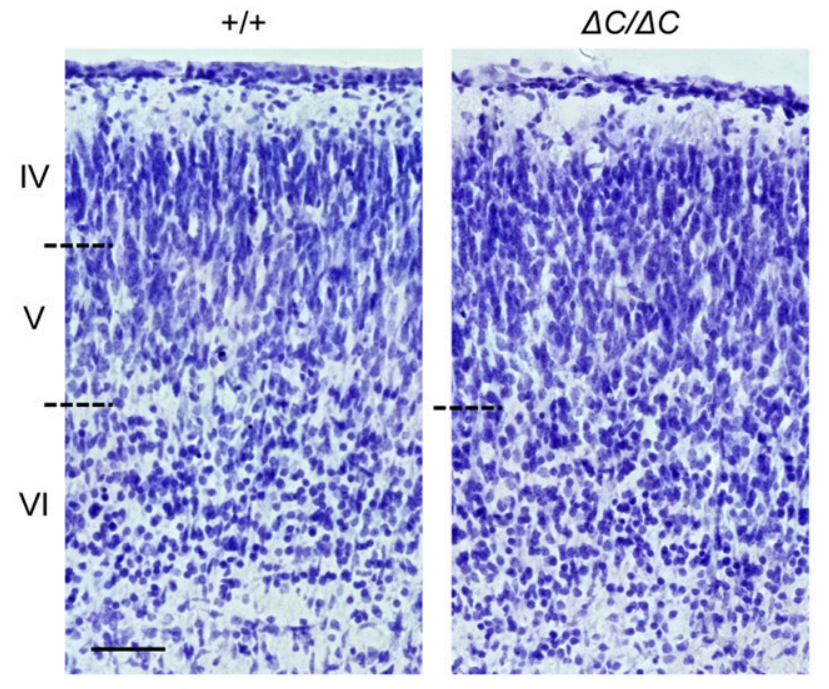

Figure 1. Targeted disruption of the mouse Pex14 gene.

(A) Schematic representation of the Pex14 genome locus (top), targeting vector (pMC-KO, middle), and targeted allele of the mutated locus following the homologous recombination (bottom). Exon sequences are indicated by black bars and boxes. (B) PCR-based genotyping using tail-derived DNA of wild-type (+/+), heterozygous $(+/ \Delta C)$, and homozygous $(\Delta C / \Delta C)$ Pex14 mutant mice. Arrows indicate the sequences used for primers described in the Materials and Methods section. Primers P14F (F) and P14R (R) amplify a 599-bp fragment, and primers F and KN52-2 (K) amplify a 169-bp fragment specific for the recombined Pex14 gene. (C) Schematic structure of predicted Pex14p proteins in wild-type mice, Pex14 mutant mice (Pex14p-Mut), and patients with a Pex14 nonsense mutation, C553T (Pex14p-Q185X). Gray bar, Pex5p-binding domain; brown bar, transmembrane domain (TM); yellow bar, coiled-coil domain (CC); shaded area, altered amino acid sequence caused by a frameshift mutation (129-163). (D) Phenotypic appearance of Pex14 mutant mice $12 \mathrm{~h}$ after birth. Scale bar, $1 \mathrm{~cm}$. (E) Postnatal body weights were determined at P0.5. The number of pups with each genotype is indicated. ${ }^{* * *} P<0.001$, by Dunnett's test compared with $+/+$. (F) Cresyl violet staining of a coronal section of the cortex from a P0.5 mouse. The open arrows indicate accumulated neurons in the intermediate zone (IZ). Scale bar, $100 \mu \mathrm{m}$. (G) Enlarged view of the boxed regions in F. Cortical layers are indicated on the left. The boundaries of the cortical plates are indicated by dashed lines. Scale bar, $50 \mu \mathrm{m}$. CP, cortical plate; DT-A, diphtheria toxin A cassette; Neo', Neomycin-resistant gene; VZ, ventricular zone. 
A

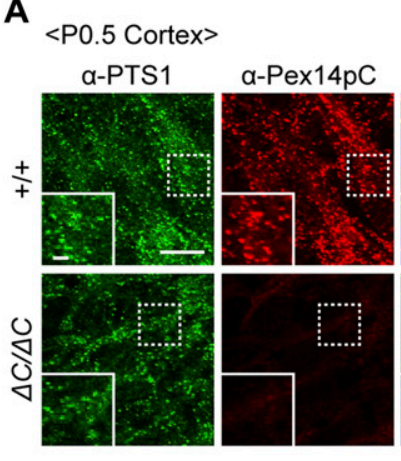

C
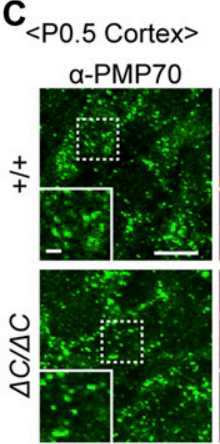

E
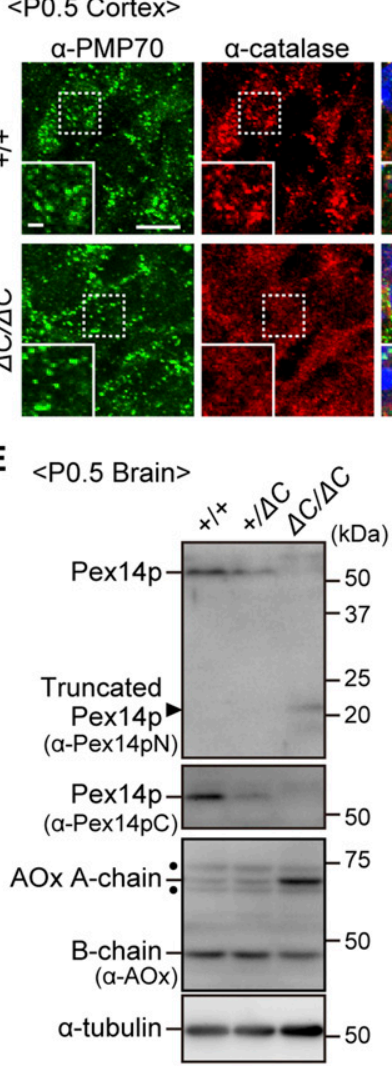

B $<$ P0.5 Cortex>
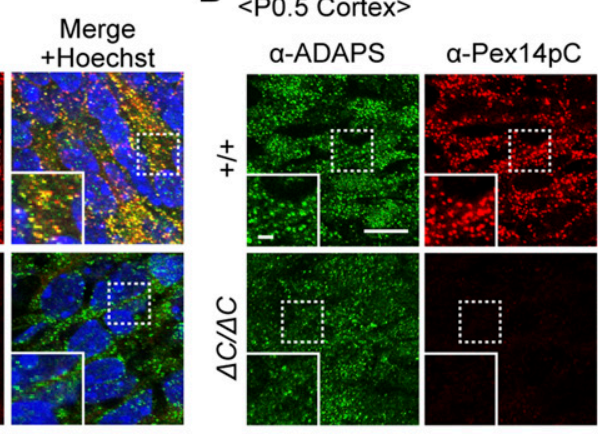

Merge + Hoechst
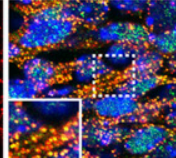

D

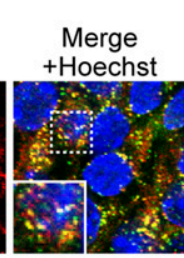

<P0.5 Cortex>

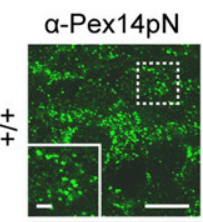

$a-P e x 14 p C$
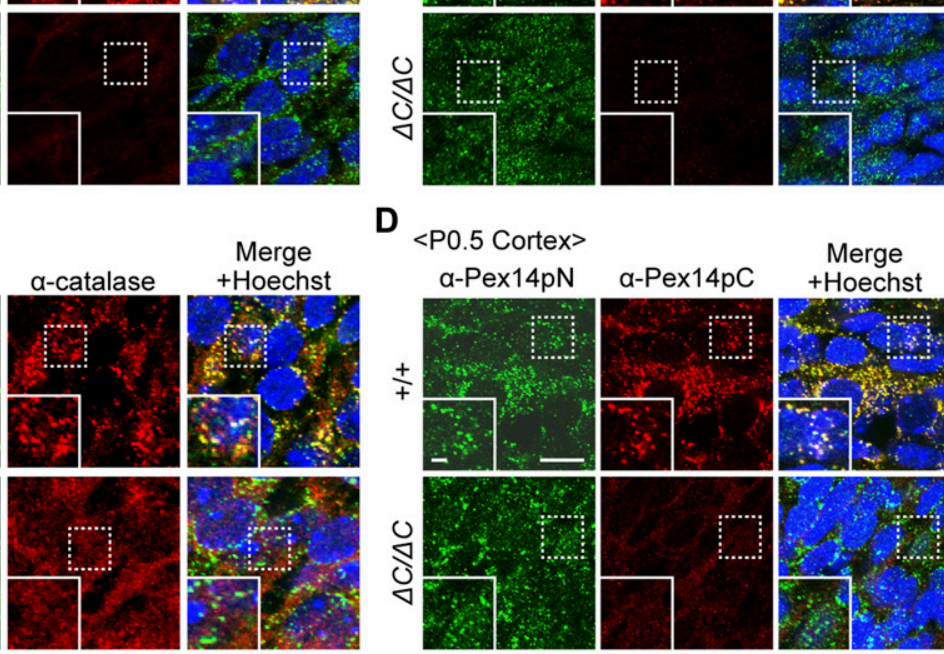

$\mathbf{F}$

$\mathbf{F}$

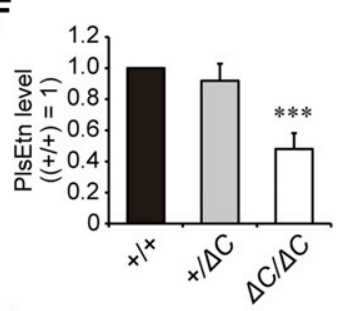

H

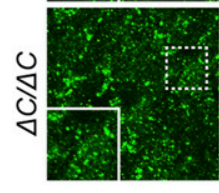

G

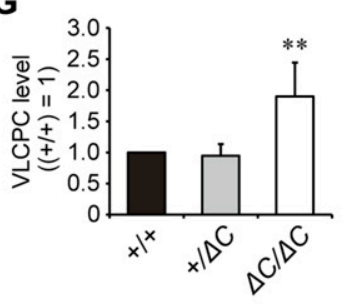

Figure 2. Impaired peroxisomal biogenesis in the cortex of Pex14 ${ }^{\Delta C / \Delta C}$ mice.

Immunofluorescence labeling of the cortex in wildtype $(+/+)$ and Pex $14^{\Delta C / \Delta C}(\Delta C / \Delta C)$ mice. (A-D) The coronal sections of brains were stained with antibodies to PTS1 (green) and Pex14pC (red) (A), ADAPS (green) and Pex14pC (red) (B), PMP70 (green) and catalase (red) (C), or Pex14pN (green) and Pex14pC (red) (D). Staining with Hoechst 33242 (blue) and the merged view are also shown. Scale bar, $10 \mu \mathrm{m}$. Higher magnification images of the boxed regions are shown (insets). Scale bar, $2 \mu \mathrm{m}$. (E) Brain lysates prepared from wild-type, heterozygous $(+/ \Delta C)$, and homozygous Pex14 mutant mice were subjected to SDS-PAGE and immunoblotting analysis using antibodies against Pex14pN, Pex14pC, AOx, and $\alpha$-tubulin. Arrowhead indicates C-terminally truncated Pex14p corresponding to Pex14p-Mut. AOx is synthesized as a $75-\mathrm{kD}$ A-chain and converted to a 53-kD B-chain and a 22-kD C-chain in peroxisomes. AOx A and AOx B chains are shown in immunoblots. Dots, non-specific bands. (F-H) Total amounts of PlsEtn (F), VLCPC (G), and DHA-PLS $(H)$ are represented relative to those in the wild-type mouse brain $(n=3) .{ }^{* *} P<0.01,{ }^{* * *} P<0.001$, by Dunnett's test compared with $+/+$

Source data are available for this figure.

\section{Prolongation of lifespan by replacing the genetic background}

Faust (2003) reported that replacement of the Pex2-null allele in a C57BL/ $6 \times 129$ Sv background to Swiss Webster $\times 129$ SvEv genetic background prolonged lifespan. Thus, a Pex14 ${ }^{+/ \Delta C}$ mouse on a C57BL/ 6 background was mated with a wild-type mouse on an ICR Swiss background, termed the C57BL/ $6 \times I C R(B L / I C R)$ strain. Breeding of heterozygous $\mathrm{BL} / \mathrm{ICR}$ mice generated homozygous mutant $\mathrm{BL} / \mathrm{ICR}$ newborn mice, termed Pex $14^{\triangle C / \Delta C}$ BL/ICR mouse, $30 \%$ of which survived over P7 but rarely survived to P14 (Fig 3A). Pups of Pex14 $4 C / \Delta C$ $\mathrm{BL} / \mathrm{ICR}$ mice exhibited severe growth retardation (Fig $3 \mathrm{~B}$ ), regardless of normal suckling activity for several days after the birth, suggesting that the primary cause for the neonatal death is not likely the feeding. This prolongation of the lifespan enabled us to analyze the cerebellar morphologies in Pex14 ${ }^{\Delta C / \Delta C} \mathrm{BL} /$ ICR mice.

\section{Malformation of the cerebellum in $\operatorname{Pex} 14^{\Delta C / \Delta C} \mathrm{BL} / \mathrm{ICR}$ mice}

Pex $14^{\Delta C / \Delta C} \mathrm{BL} / \mathrm{ICR}$ mice displayed the defects of cerebellar development, including atrophy of the cerebellar folia (Fig 3C), the migration delay of granule cells as suggested by thickening of the external granular layer (Fig 3D and E) and malformation of Purkinje cells at P3 (Fig 3F and G) and P7 (Fig 3I). In wild-type mice at P3, Purkinje cells began to polarize and show elongated cell soma and major dendrites (Fig 3F), and their axons projected into the internal granular layer (IGL, Fig 3G, left panel, arrows). By contrast, Purkinje cells at P3 in Pex $14^{\triangle C / \Delta C} \mathrm{BL} /$ ICR mice were less polarized, the soma was smaller (Fig 3F), and axonal swelling was evident (Fig $3 \mathrm{G}$ and $\mathrm{H}$, arrowheads). At P7, impairment of Purkinje cell arborization was more evident and axonal reticular structures were observed in the IGL region (Fig 3I). Such dysmorphogenesis 
A

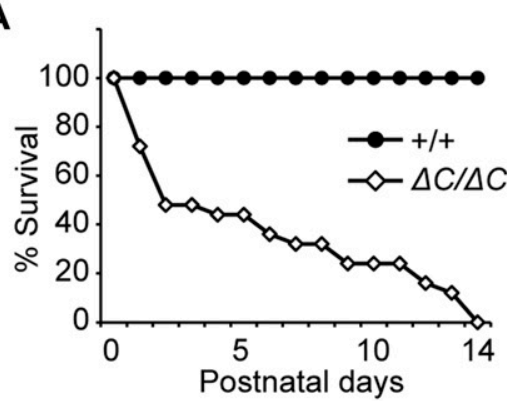

C

$<$ P7 Cerebellum >
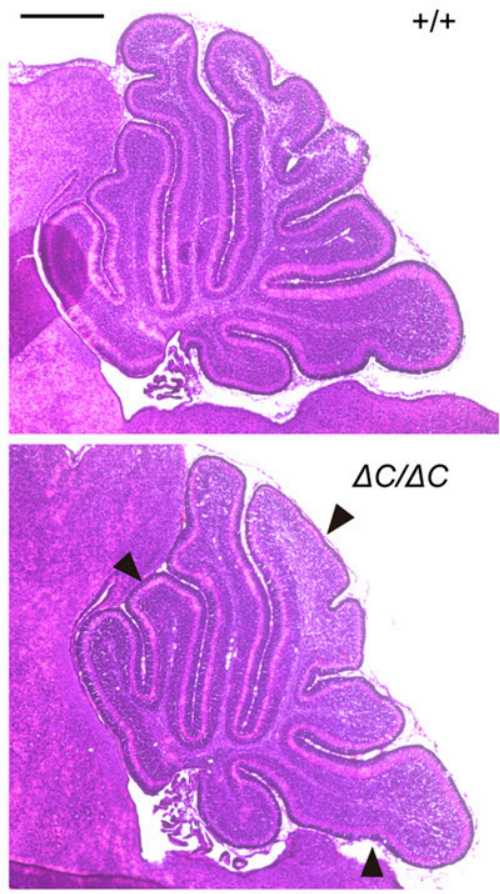

G

$<$ P3 Cerebellum >
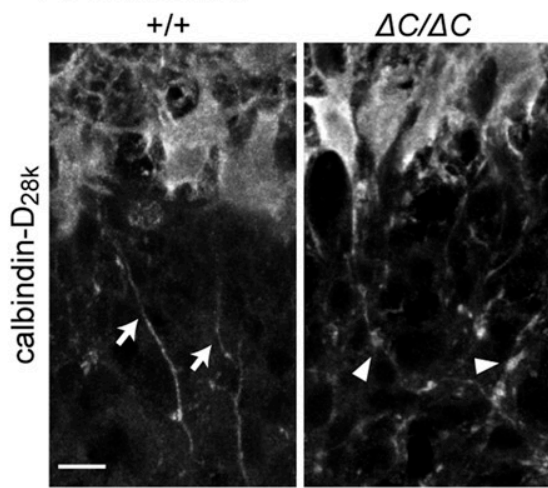

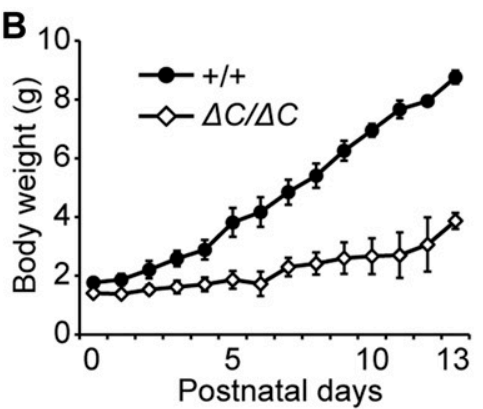

D

$<$ P7 Cerebellum >
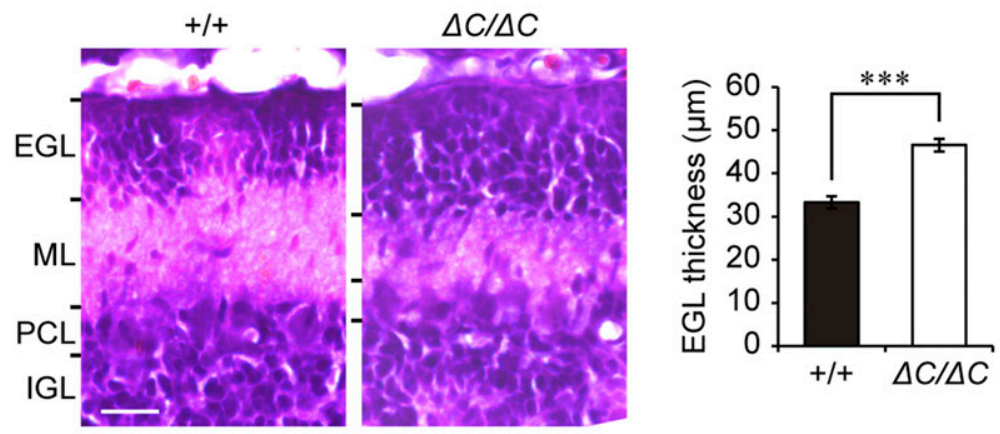

F

<P3 Cerebellum>
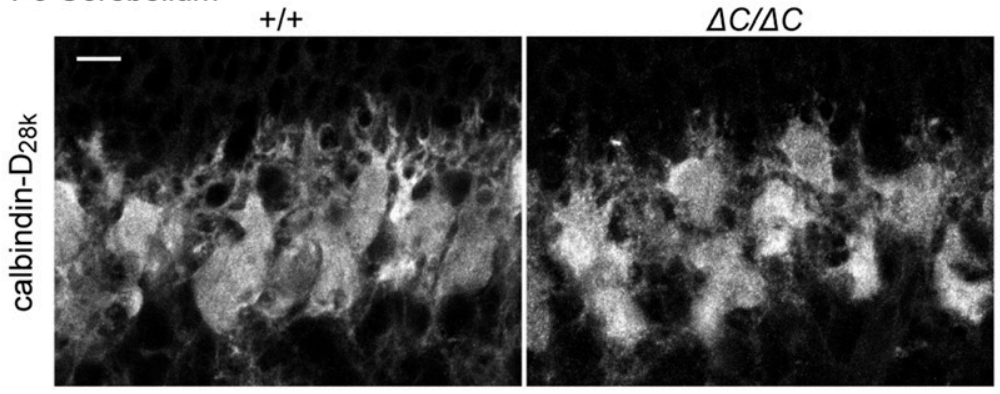

H

I $<$ P7 Cerebellum>
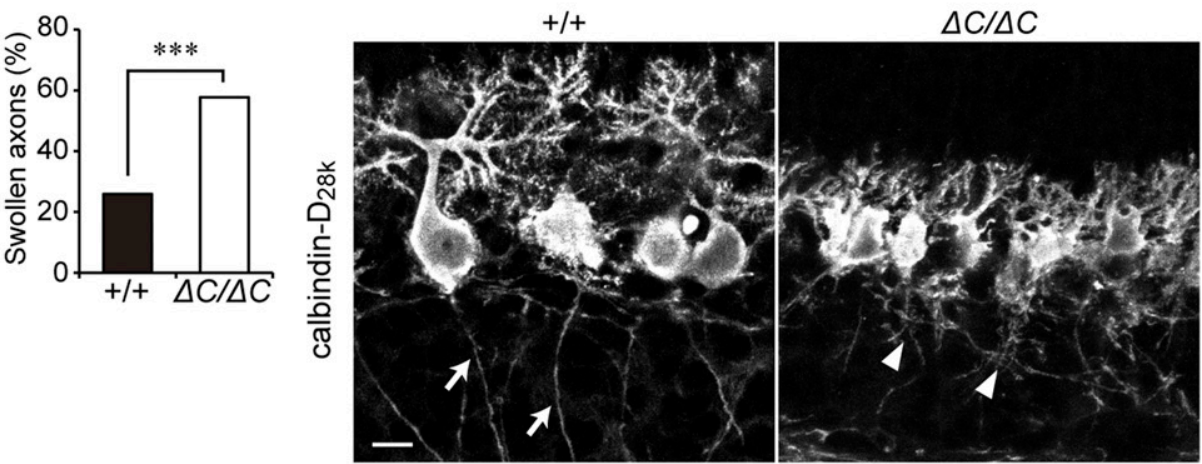

Figure 3. Defect of cerebellar development and malformation of Purkinje cells in Pex14 ${ }^{\Delta C / \Delta C} \mathrm{BL} / \mathrm{ICR}$ mice.

(A) Percentage of pups surviving at postnatal days. The survival days were based on the pups of 22 wild-type $(+/+)$ and 25 Pex $14^{\Delta C / \Delta C}(\Delta C / \triangle C) B L / I C R$ mice. (B) Body weights of pups at postnatal days were plotted. (C) Hematoxylin and eosin staining of the sagittal sections of the cerebellum (P7). Arrowheads indicate the shallow cerebellar folia in the cerebellum of the Pex $14^{\Delta C / \Delta C}$ BL/ICR mouse (lower panel). Scale bar, $500 \mu \mathrm{m}$. (D) The sagittal section of the cerebellum at P7 was stained with hematoxylin and eosin. Scale bar, $20 \mu \mathrm{m}$. (E) Thickness of EGL was quantified $(n=3)$. $(\mathbf{F}, \mathbf{G})$ Confocal microscopy images of the sagittal sections of the 
of Purkinje cells in the postnatal period indicated the defect of cerebellar development, consistent with the results of earlier studies examining Pex2- and Pex13-knockout mice (Faust, 2003; Müller et al, 2011).

\section{Peroxisome biogenesis deficiency elevates BDNF expression in neuroblastoma cells}

We next examined whether peroxisome biogenesis deficiency alters the neuronal morphology using a neuroblastoma cell line, SH-SY5Y. Knockdown of PEX5 encoding, an essential cytosolic receptor that binds to Pex14p for import of matrix proteins (Fig 4A), impaired peroxisome biogenesis as indicated by the reduced localization of catalase in peroxisomes (Fig 4B) and induced the cell dispersion and the enhancement of neurite outgrowth in SH-SY5Y (Fig 4C, upper panels). This morphological alteration of $\mathrm{SH}-\mathrm{SY} 5 \mathrm{Y}$ resembled the BDNF-induced neurite outgrowth on the SH-SY5Y cells (Kaplan et al, 1993). Therefore, we focused on neurotrophins, including NGF, BDNF, neurotrophin 3 (NT-3), and NT-4 (Reichardt, 2006). The neurite outgrowth in SH-SY5Y cells transfected with siRNA against PEX5 was suppressed by inhibiting the binding of these neurotrophins to their receptors in the presence of recombinant extracellular domain of the p75 neurotrophic receptor (p75ECD-His), common receptor for the neurotrophins (Fig 4C, lower panels) (Reichardt, 2006), suggesting the involvement of neurotrophins in the neurite outgrowth. Real-time PCR revealed that knockdown of PEX5 elevated BDNF expression but not other neurotrophins, including NGF, NT-3, and NT-4 (Fig 4D). The intracellular level of BDNF was also increased in PEX5-depleted cells (Fig 4E). Moreover, the neurite outgrowth was promoted upon culturing cells in the conditioned medium from PEX5-depleted SH-SY5Y cells (Fig 4F, upper panels) and medium containing recombinant BDNF (rBDNF, Fig 4G). However, such morphological changes were suppressed in the presence of p75ECD-His (Fig 4F and G). Taken together, these results suggested that elevated secretion of BDNF from the cells impaired peroxisome biogenesis induced neurite outgrowth in neuronal cells and prompted us to examine the effect of elevated BDNF on neuronal development in the mice defective in peroxisome biogenesis.

\section{Excess BDNF impairs development of dendrites in Pex14-deficient Purkinje cells}

To investigate whether the malformation of the cerebellum in Pex14 ${ }^{\triangle C / \Delta C} \mathrm{BL} / \mathrm{ICR}$ mice is a consequence of the elevated BDNF protein level, we labeled BDNF in sagittal sections of the cerebellum in P3 mice. BDNF was detected around the Purkinje cell layer in the wild-type mouse, as previously reported (Friedman et al, 1998), and elevated in Pex $14^{\Delta C / \Delta C} \mathrm{BL} / I C R$ mice (Fig $5 A$ and B). To assess the effect of excess BDNF on the development of Purkinje cells in
Pex $14^{\Delta C / \Delta C} \mathrm{BL} / \mathrm{ICR}$ mouse, we performed primary culture of cerebellar cells. Primary cerebellar neurons isolated from neonatal mouse cerebella (P0.5) were cultured for $14 \mathrm{~d}$ in vitro (DIV) in the absence or presence of $\mathrm{rBDNF}$ at $50 \mathrm{ng} / \mathrm{ml}$, which is in a range similar to that estimated from concentration of BDNF in rat cerebellum ( 10 ng/ml) (Baranowska-Bosiacka et al, 2013). Cerebellar neurons were fixed and stained with anti-calibindin- $D_{28 k}$ antibody to visualize Purkinje cells (Fig $5 \mathrm{C}-\mathrm{H}$ ). The axonal elongations and collateral formations were not apparently induced by the treatment with BDNF (Fig 5C-E). Rather, Purkinje cells with swollen axons (Fig $5 \mathrm{C}$, inset) were more frequently detected upon treatment with BDNF of the cells from Pex14 ${ }^{\Delta C / \Delta C}$ BL/ICR mouse (Fig 5F). Moreover, the development of dendrites in the Pex14-defective Purkinje cells was affected in the presence of BDNF (Fig 5G), as determined by the area of Purkinje cell soma and dendrites (Fig $5 \mathrm{H}$ ). In the wild-type Purkinje cells, the axonal formation and dendritic arborization were not altered by the BDNF treatment (Fig 5C-H). Such dysmorphologies of Purkinje cells in vitro were consistent with those observed in the cerebella of Pex $14^{\Delta C / \Delta C} \mathrm{BL} / \mathrm{ICR}$ mice (Fig 3F-I). Taken together, these results suggested that peroxisome deficiency in Purkinje cells induces the dysregulation of the BDNF signaling pathway in the presence of an elevated level of BDNF, leading to the axonal swelling and the defect of dendritic arborization.

\section{BDNF-TrkB signaling pathway is attenuated in the cerebellum of Pex14-deficient mice}

BDNF regulates cell growth and axonal outgrowth via binding to tropomyosin-related kinase $B$ (TrkB) receptor on the neuronal surface (Reichardt, 2006). Functionally, TrkB-defective mutant mice show significant reduction in dendritic arborization of Purkinje cells (Minichiello \& Klein, 1996; Rico et al, 2002). Therefore, the BDNF-TrkB signaling pathway is most likely essential for early postnatal development of the cerebellum, especially in the dendritic branching of Purkinje cells (Minichiello \& Klein, 1996; Schwartz et al, 1997; Carter et al, 2002; Rico et al, 2002; Sherrard \& Bower, 2002).

We next investigated whether expression of TrkB is affected in the cerebellum of $P \operatorname{ex} 14^{\Delta C / \Delta C} B L / I C R$ mice. Immunofluorescent staining of TrkB revealed that TrkB-labeled punctate structures were detected on the IGL side of Purkinje cell soma in the wild-type cerebellum at P3 (Fig 6A, arrowheads). Vesicular glutamate transporter 2 (vGlut2), a marker for climbing fiber terminals, was detected in the same region of Purkinje cells (Fig 6C), suggesting the localization of TrkB on the climbing fiber-Purkinje cell (CF-PC) synapse (Sherrard et al, 2009). Indeed, TrkB-labeled punctate structures partly coincided with or are located adjacent to vGlut2positive punctate structures (Fig 6D, arrowheads). At P7, TrkBpositive punctate structures were not readily detectable (Fig S3A) and vGlut2 was mainly localized in the dendrite of the Purkinje cells (Fig S3B), suggesting that climbing fiber terminals shifted to the

cerebellum at P3 labeled with an antibody to calbindin- $D_{28 k}$, a Purkinje cell marker. Arrows indicate axons of wild-type Purkinje cells and arrowheads indicate swollen axons of Pex14 mutant Purkinje cells. Scale bar, $10 \mu \mathrm{m}$. (H) Percentage of swollen axons was quantified $(+/+, \mathrm{n}=54 ; \Delta C / \Delta C, \mathrm{n}=52)$. (I) Confocal microscopy images of sagittal sections of the cerebellum at P7 labeled with an antibody to calbindin- $D_{28 k}$ are shown. Arrows indicate axons of wild-type Purkinje cells and arrowheads indicate axonal reticular structures of Pex14 mutant Purkinje cells. Scale bar, $10 \mu \mathrm{m} .{ }^{* * *} \mathrm{P}<0.001$, by $t$ test $(\mathrm{E})$ and $x^{2}$ test $(\mathrm{H})$. EGL, external granular layer; IGL, internal granular layer; ML, molecular layer; PCL, Purkinje cell layer. 
A

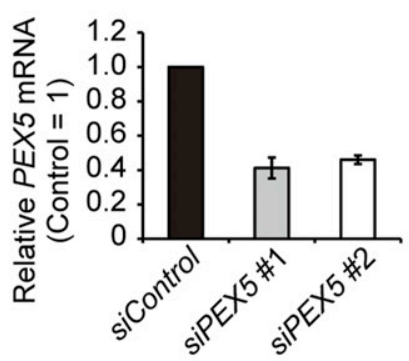

C

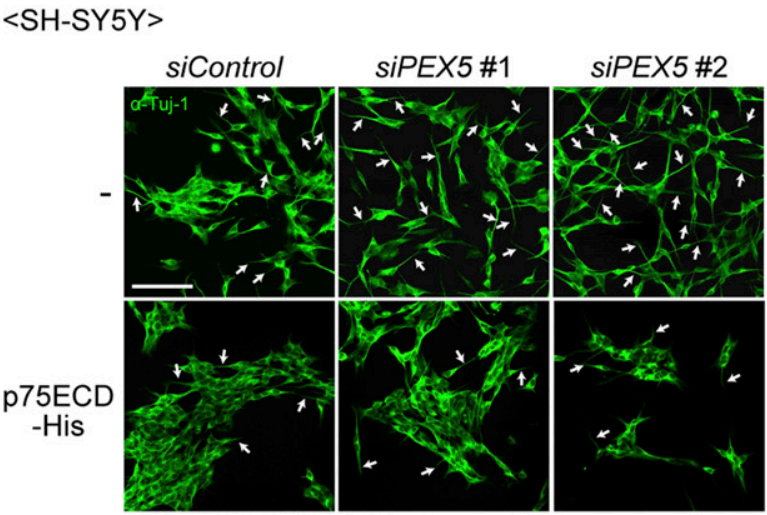

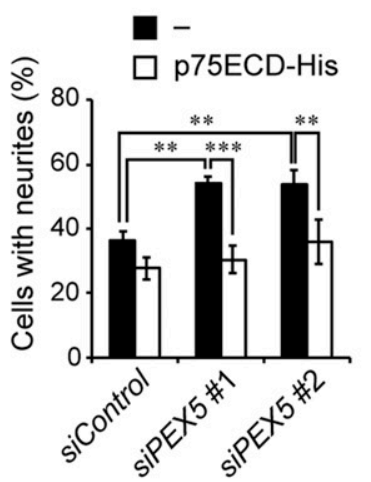

B

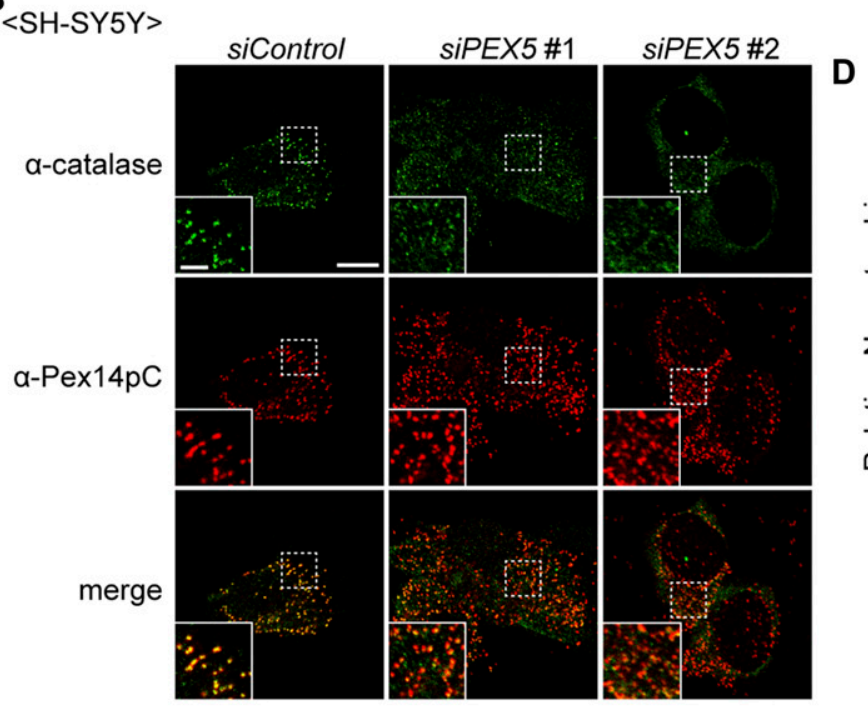

$\mathbf{F}$

$<$ SH-SY5Y>
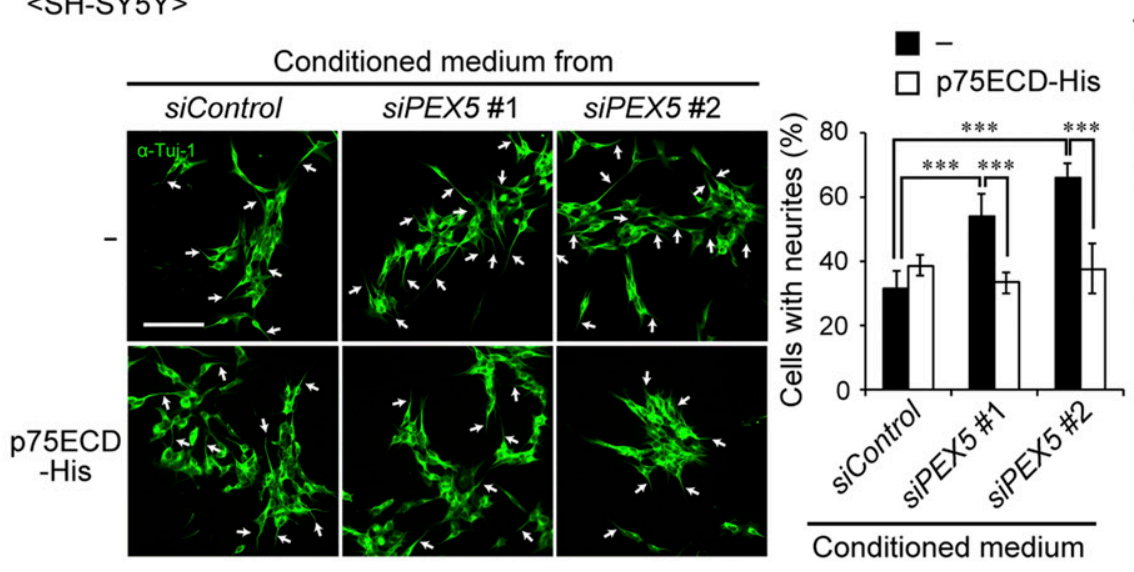

G

E

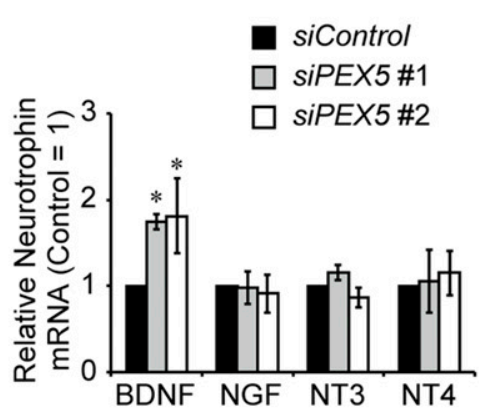

$<\mathrm{SH}-\mathrm{SY} 5 \mathrm{Y}>$

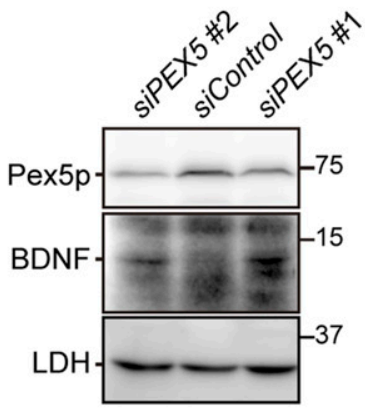

$<$ SH-SY5Y $>$
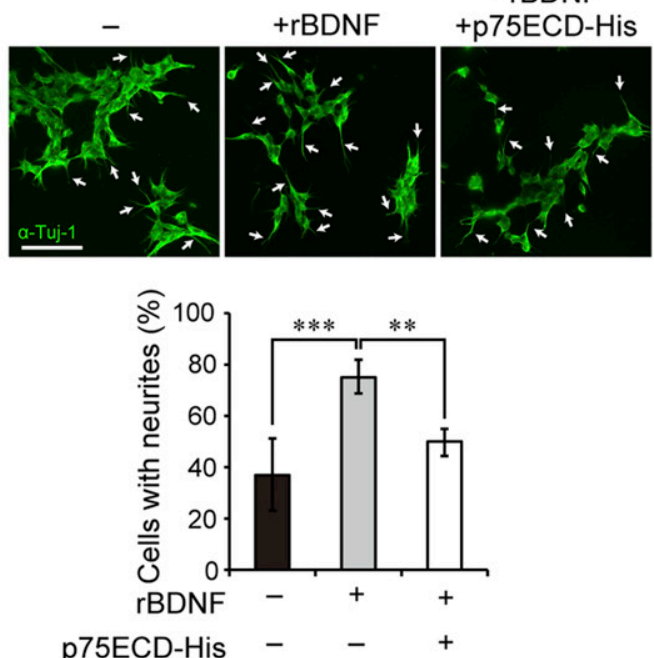

Figure 4. Up-regulation of BDNF induces the neurite outgrowth of SH-SY5Y cells.

(A) SH-SY5Y cells were treated with a control siRNA (siControl) or siRNAs against PEX5 (\#1 and \#2) and cultured for 48 h. PEX5 mRNA level was determined by real-time PCR $(n=3)$. (B) Cells were stained with anti-catalase (green) and Pex14pC (red) antibodies. Scale bar, $10 \mu \mathrm{m}$. Higher magnification images of the boxed regions are shown (inset). Scale bar, $2 \mu \mathrm{m}$. (C) SH-SY5Y cells treated with siRNAs were cultured in the presence or absence of the recombinant extracellular domain of 
A $<\mathrm{P} 3$ Cerebellum $>$

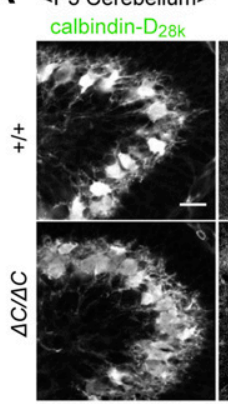
BDNF

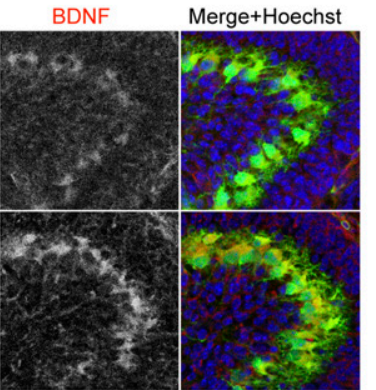

C

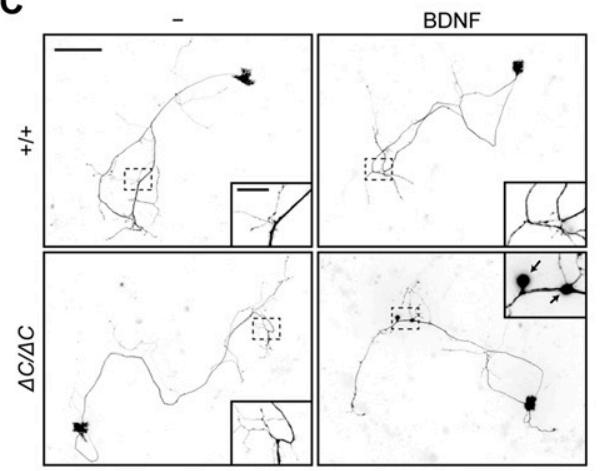

G

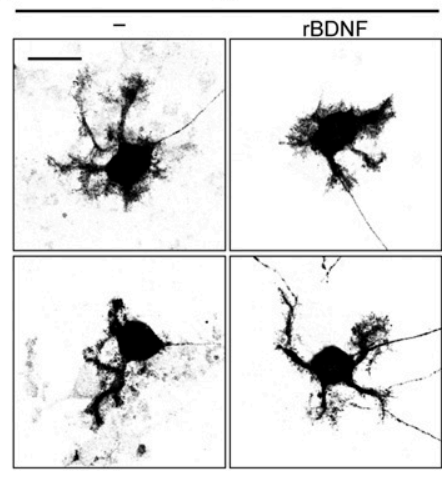

B

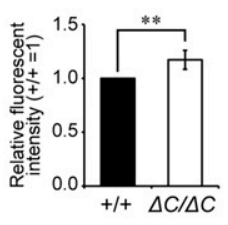

D
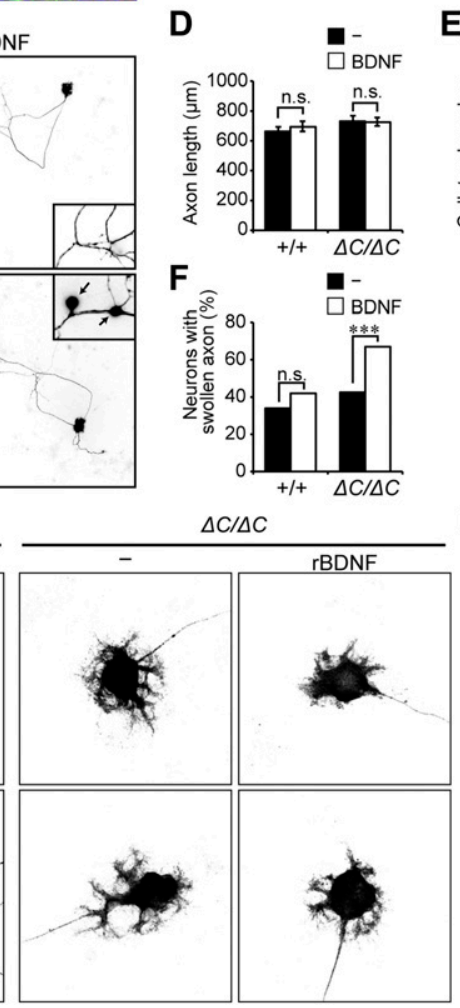

E

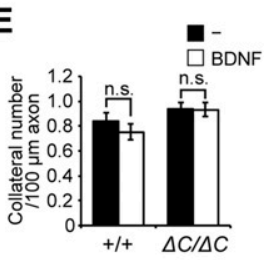

E

H

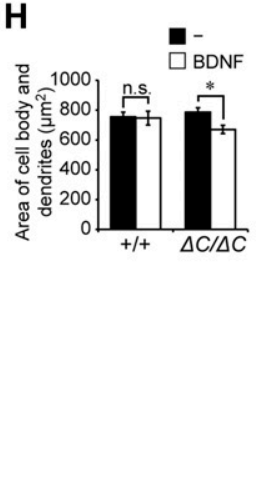

Figure 5. Axonal swelling and impairment of dendritic development in Purkinje cells from Pex $14^{\Delta C / \Delta C}$ BL/ICR mouse upon treatment with BDNF. (A) Sagittal sections of the cerebellum from wild-type $(+/+)$ and $P \operatorname{ex} 14^{\Delta C / \Delta C}(\Delta C / \Delta C) B L / I C R$ mice were labeled with anti-calbindin- $\mathrm{D}_{28 \mathrm{~K}}$ (left panels, green) and BDNF (middle panels, red) antibodies. Merged views of the two different proteins and staining with Hoechst 33242 (blue) are shown on the right. Scale bar, $50 \mu \mathrm{m}$. (B) Relative fluorescent intensity of BDNF was quantified $(n=4)$. (c) Primary cerebellar neurons were cultured in the absence or presence of $50 \mathrm{ng} / \mathrm{ml}$ BDNF for 14 DIV. The cells were fixed and stained with antibody against calbindin- $D_{28 k}$. Reverse images of Purkinje cells are shown. Scale bar, $100 \mu \mathrm{m}$. Higher magnification image of the boxed region is shown in the inset. Arrows indicate swollen axons of Purkinje cell. Scale bar, $20 \mu \mathrm{m}$. (D, E) Statistical analyses were performed for neuronal axon length (D) and the number of collaterals per $100-\mu \mathrm{m}$ axon (E). Data represent means \pm SEM. (F) The percentage of swollen axons ( $>2 \mu \mathrm{m}$ diameter) was quantified. (G) Enlarged view of the reverse images of Purkinje cell bodies are shown (upper and lower panels). Scale bar, $20 \mu \mathrm{m}$. (H) Areas of the cell body and dendrites of Purkinje cells were measured (+/+: $n=64 ;+/+, r B D N F: n=42 ; \Delta C / \Delta C: n=110$; $\triangle C / \triangle C, r B D N F: n=109)$. Data represent means \pm SEM. $n s$, not significant, ${ }^{*} P<0.05,{ }^{* *} P<0.01,{ }^{* * *} P<0.001$, by $t$ test (B), Tukey-Kramer test $(D, E, H)$, and $x^{2}$ test (F). dendritic compartment of Purkinje cells. Contrary to these observations, TrkB-positive punctate structures were apparently decreased in the Pex $14^{\Delta C / \Delta C}$ cerebellum at P3 (Fig 6A, B, and D) and P7 (Fig S3A). vGlut2-positive dots were reduced in number around Purkinje cells at P3 (Fig 6C) and remained on the IGL side of cell soma at P7 in Pex $14^{\Delta C / \Delta C} B L / I C R$ mice (Fig S3B). Given that TrkB activity is thought to be involved in the promotion of CF-PC synaptic formation and stabilization (Sherrard et al, 2009), these results suggested that the deficiency of peroxisomal biogenesis gave rise to perturbation of the CF-PC synapse through dysregulation of the BDNF-TrkB signaling pathway.

Two splicing variants of TrkB are abundantly expressed in the brain, and each variant functions in different cellular processes (Klein et al, 1990). Upon activation, full-length TrkB with its tyrosine kinase domain (TrkB-TK+) facing to the cytosol stimulates the MAPK/ERK, PI3K/AKT, and PLCY pathways that regulate neuronal survival and differentiation (Numakawa et al, 2010). By contrast, the cytosolic domain-truncated TrkB isoform (TrkB-T1) induces

p75NTR (p75ECD-His, amino acid sequence at 1-747) and stained with anti-Tuj-1 antibody (green). Arrows indicate neurons with neurite outgrowth. Percentage of neurons with neurite outgrowth were determined and shown on the right ( $n>100$ cells; three cultures each). Scale bar, $100 \mu$ m. (D) mRNA levels of neurotrophins in SH-SY5Y cells were assessed by real-time PCR $(n=3)$. (E) SH-SY5Y cell lysates were analyzed by SDS-PAGE and immunoblotting with antibodies against Pex5p, BDNF, and LDH. (F) Conditioned medium was obtained from the culture of SH-SY5Y cells treated with siRNAs that had been cultured for $2 \mathrm{~d}$. SH-SY5Y cells were incubated in the collected conditioned medium in the presence or absence of p75ECD-His for $2 \mathrm{~d}$. Percentages of neurons with neurite outgrowth were determined and shown on the right ( $n>100$ cells; three cultures each). Scale bar, $100 \mu \mathrm{m}$. (G) SH-SY5Y cells were cultured in the presence or absence of recombinant BDNF (rBDNF) and p75ECD-His. Cells were stained with anti-Tuj-1 antibody (green, upper panels). Percentages of neurons with neurite outgrowth were shown in a lower panel ( $\mathrm{n}>100$ cells; five cultures each). Scale bar, $100 \mu \mathrm{m}$. Data represent means \pm SD. ${ }^{*} P<0.05,{ }^{* *} P<0.01,{ }^{* *} P<0.001$, by Tukey-Kramer test $(C, F, G)$ and Dunnett's test (D).

Source data are available for this figure. 
A $<$ P3 Cerebellum $>$
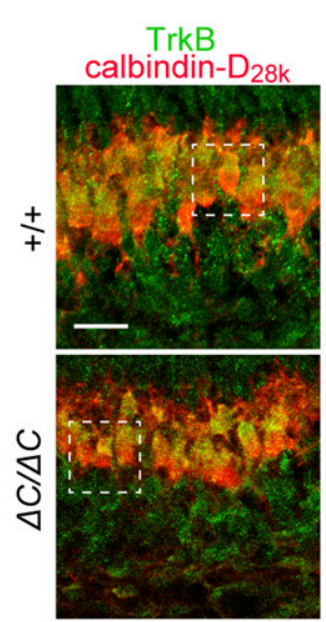

D
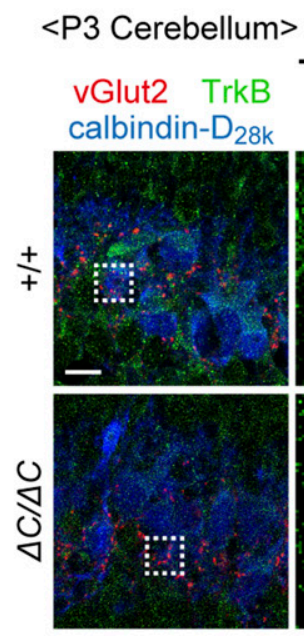

E

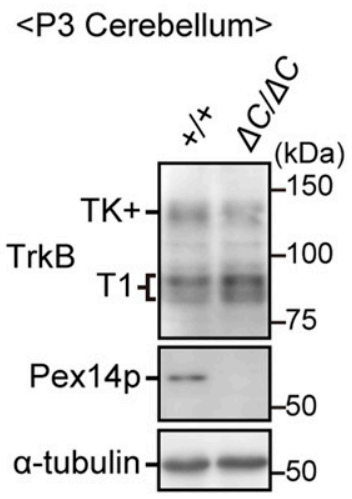

B
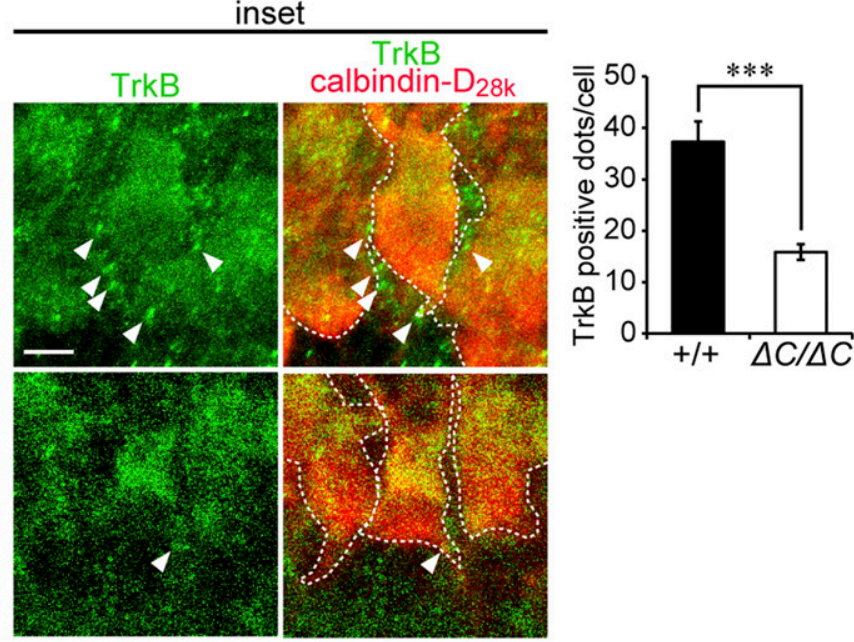

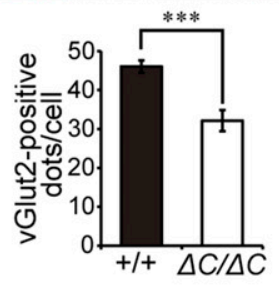

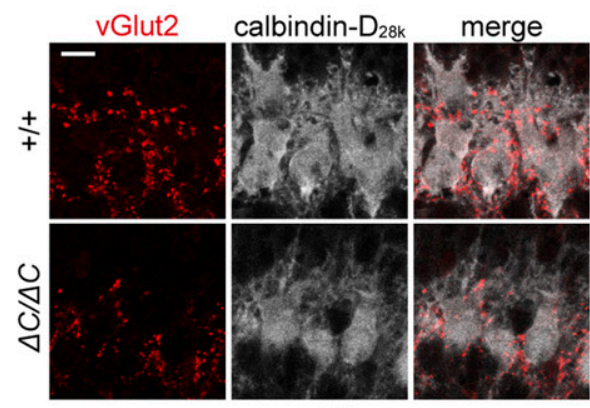

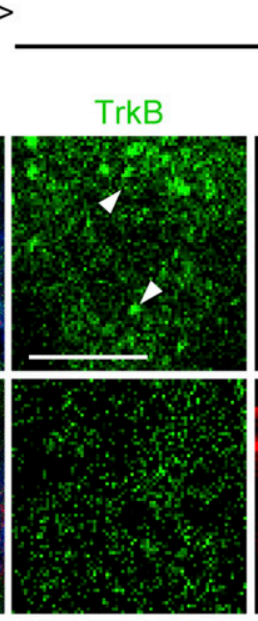

Inset

C $<$ P3 Cerebellum >

F

$<$ P3 Cerebellum >

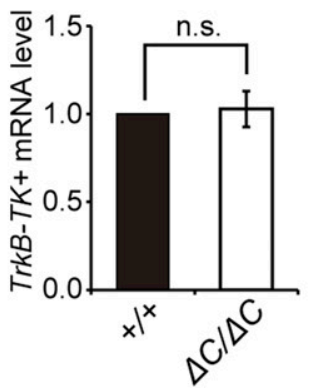

G

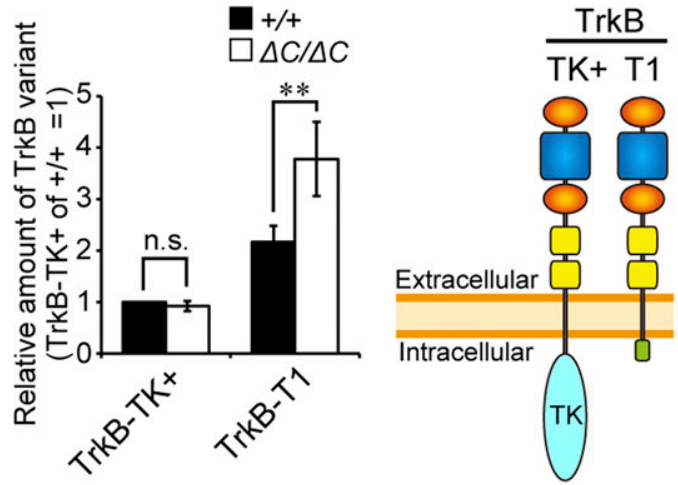

<P3 Cerebellum>

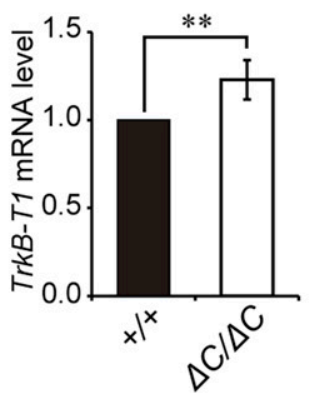

Figure 6. TrkB-T1 is upregulated in cerebellum of Pex14 ${ }^{\Delta C / \Delta C} \mathrm{BL} / \mathrm{ICR}$ mouse at P3.

(A) Sagittal sections of the cerebellum from wild-type $(+/+)$ and Pex $14^{\Delta C / \Delta C}(\Delta C / \Delta C) B L / I C R$ mice were labeled with anti-TrkB (green) and calbindin- $D_{28 k}$ (red) antibodies. Scale bar, $20 \mu \mathrm{m}$. Higher magnification images of the boxed regions are shown and cell boundaries were indicated as a dashed line (inset). Scale bar, $5 \mu \mathrm{m}$. (B) TrkB-positive dots (arrowheads) were quantified $(n=13)$. (C) Sagittal sections of the cerebellum at P3 were stained with antibodies against vGlut2 (red) and calbindin-D28k (white). The number of dots stained with anti-vGlut2 antibody was quantified (lower panel, $\mathrm{n}=4$ ). Scale bar, $10 \mu \mathrm{m}$. (D) Sagittal sections of the cerebellum at P3 were stained with antibodies against TrkB (green), vGlut2 (red), and calbindin- $D_{28 k}$ (blue). Scale bar, $10 \mu$ m. Higher magnification images of the boxed regions are shown (inset). Scale bar, $5 \mu \mathrm{m}$. Arrowheads indicate TrkB-positive punctate structures that partly coincided with or are located adjacent to vGlut2-positive punctate structures. (E) Cerebellum lysates were analyzed by SDS-PAGE and immunoblotting with antibodies against TrkB, Pex14pC, and $\alpha$-tubulin (left panel). TrkB-TK+, full-length TrkB; TrkB-T1, a truncated isoform of TrkB. Amounts of TrkB-TK+ and TrkB-T1 are presented relative to those of TrkB-TK+ in the control mice (middle panel, $n=6$ ). 
A

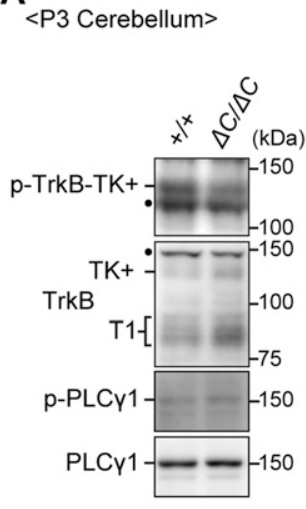

B

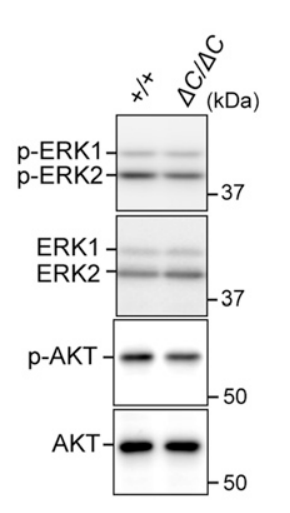

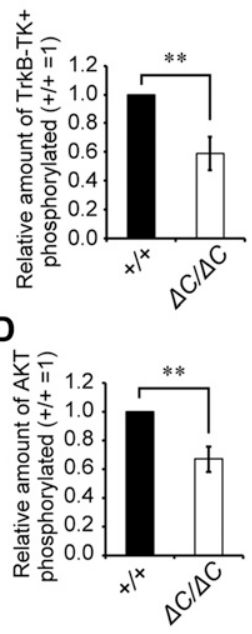

C

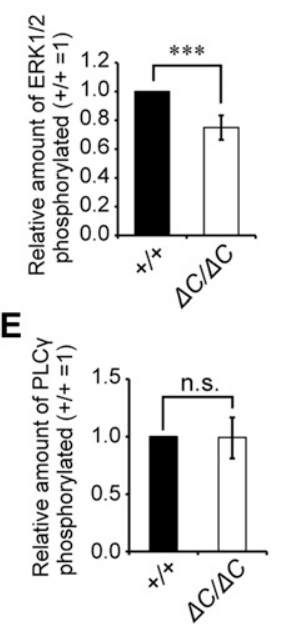

Figure 7. The BDNF-TrkB signaling pathway is impaired in the cerebellum of Pex14 ${ }^{\Delta C / \Delta C} B L / I C R$ mice at P3.

(A) Cerebellum lysates from wild-type $(+/+)$ and $\operatorname{Pex} 14^{\Delta C / \Delta C}(\Delta C / \Delta C) B L / I C R$ mice were analyzed by SDS-PAGE and immunoblotting with antibodies against TrkB, phosphorylated Trk (p-TrkB-TK+, Y496), PLCY1, phosphorylated PLCY1 (p-PLCY1, Y783), ERK, phosphorylated ERK ( $p$-ERK1 and 2, T202 and Y204, respectively), AKT, and phosphorylated AKT ( $p$-AKT, S473). Dots, non-specific bands. (B-E) The amount of phosphorylated TrkB-TK+ to total TrkB-TK+ (B), phosphorylated ERK1/2 relative to total ERK1/2 (C), phosphorylated AKT to total AKT (D), and phosphorylated PLCY1 to total PLCY1 (E) were represented $(\mathrm{n}=3)$. ns, not significant, ${ }^{* \star} P<0.01,{ }^{\star \star *} P<$ 0.001 , by $t$ test (B-E).

Source data are available for this figure. dominant-negative inhibition of TrkB-TK+ signaling and negatively regulates cytoskeletal rearrangement (Eide et al, 1996; Fryer et al, 1997; Fenner, 2012). We analyzed the expression level of TrkB variants in the cerebellum at P3. Immunoblotting analysis showed that TrkB-T1 was significantly elevated in the cerebellum of Pex $14^{\Delta C / \Delta C}$ $\mathrm{BL} / \mathrm{ICR}$ mice relative to that of wild-type mice (Fig 6E). However, there was no difference in the expression level of TrkB-TK+ between the mice of each genotype (Fig 6E and F). The up-regulation of TrkBT1 was likely caused by increased TrkB-T1 transcription (Fig 6G). Because BDNF treatment did not influence the expression of TrkB variants in the primary culture condition, TrkB-T1 elevation is apparently in a manner independent of the elevation of BDNF in the cerebellum (Fig S3C and D). To investigate whether TrkB-TK+ signaling was attenuated in the cerebellum of $\operatorname{Pex} 14^{\Delta C / \Delta C} \mathrm{BL} / \mathrm{ICR}$ mice, we investigated the phosphorylation level of TrkB-TK+, ERK1/2, AKT, and PLCY. Phosphorylated TrkB-TK+, ERK1/2, and AKT were decreased in the cerebellum of the Pex1 $4^{\Delta C / \Delta C} B L / I C R$ mouse (Fig 7A-D) and expression of $c$-fos and c-jun, target genes of the BDNFTrkB signaling pathway, was reduced as well (Fig S3E), suggesting the suppression of the TrkB-TK+ signaling pathway. The elevated level of TrkB-T1 and the deactivation of TrkB-TK+ and ERK signaling pathway were evident at P5 and P7 (Fig S3F-I). On the other hand, the phosphorylation level of PLCY was very low and not altered in Pex14 ${ }^{\Delta C / \Delta C} \mathrm{BL} / \mathrm{ICR}$ mice (Fig $7 \mathrm{~A}$ and E). Actin cytoskeleton was assessed by phalloidin-TRITC staining. In the wild-type mice, actinpositive structures were aligned on the dendritic tree of Purkinje cells (Fig S3J and K, upper panels). The number of actin-positive structures was reduced in Pex $14^{\Delta C / \Delta C} \mathrm{BL} / \mathrm{ICR}$ mice (Fig S3) and $\mathrm{K}$, lower panels), suggesting the impaired actin-based cytoskeletal organization in the Purkinje cells. Taken together, these results suggest that peroxisome deficiency most likely induces the upregulation of TrkB-T1 in Purkinje cells, leading to impairment of
BDNF-TrkB-TK+ signaling in the presence of an elevated level of BDNF, and subsequently, the malformation of Purkinje cells.

\section{Up-regulation of BDNF expression in Pex14-deficient mice}

We attempted to address how the protein level of BDNF is elevated in the cerebellum of Pex $14^{\Delta C / \Delta C} B L / I C R$ mice. The $B d n f$ mRNA level was not altered in the cerebellum (Fig 8A). The level of mRNA for NT-4, another ligand for TrkB, was much lower in the cerebellum (Fig 8A). Immunofluorescent microscopy using antibodies to glial fibrillary acidic protein (GFAP) revealed that GFAP-positive Bergmann glia cells were not co-localized with BDNF (Fig 8B). Therefore, cerebellar glia cells are less likely to be involved in the upregulation of $\mathrm{BDNF}$ in $P \operatorname{ex} 14^{\triangle C / \triangle C} \mathrm{BL} / \mathrm{ICR}$ mice. In addition, the cells expressing both GFAP and BDNF were not detectable in the cortex at P7 (data not shown). By contrast, mRNA and protein levels of BDNF were up-regulated in ION of both genetic backgrounds of Pex $14^{\Delta C / \Delta C}$ mutant mice (Fig $8 \mathrm{C}-\mathrm{H}$ ). Given these results, together with the fact that climbing fiber projects from ION to Purkinje cells (Sherrard \& Bower, 2002), we suggest that the elevated BDNF protein in the Purkinje cell layer is most likely delivered by climbing fibers.

\section{Expression of TrkB variants and BDNF is not altered in the cortex of $\operatorname{Pex} 14^{\Delta C / \Delta C}$ mice}

ZS patients and Pex-knockout mice manifest neuronal migration defect in the cortex (Baes et al, 1997; Evrard et al, 1978; Faust \& Hatten, 1997; Maxwell et al, 2003) (Fig 1F and G). TrkB was reported to be involved in the neuronal migration (Medina et al, 2004). We therefore analyzed the expression of TrkB variants in the cortex at P0.5 because cortical neuronal migration takes place from the

A schematic view of TrkB variants is shown on the right (right panel). TK, tyrosine kinase domain. (F, G) mRNA levels of TrkB-TK+ (F) and TrkB-T1 (G) were quantified by real-time PCR $(n=6)$. ns, not significant, ${ }^{* *} P<0.01,{ }^{* * *} P<0.001$, by $t$ test $(B, C, E-G)$.

Source data are available for this figure. 
A

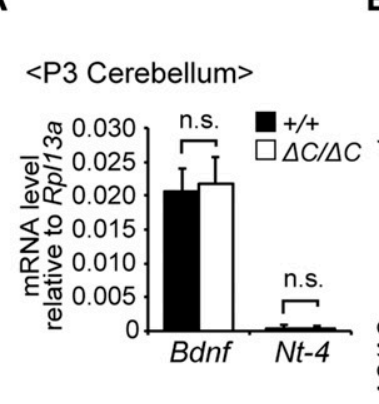

\section{C}

\section{$<$ P0.5 Brain stem ${ }_{\text {Bdnf mRNA }}$}

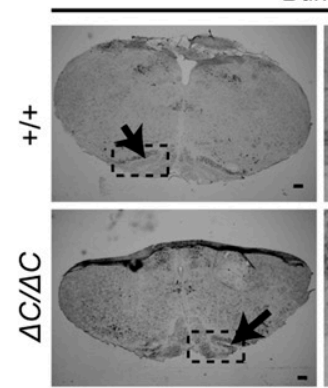

E

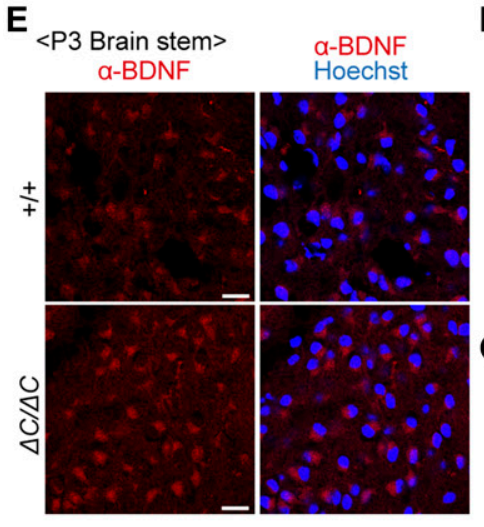

B $<$ P7 Cerebellum $>$

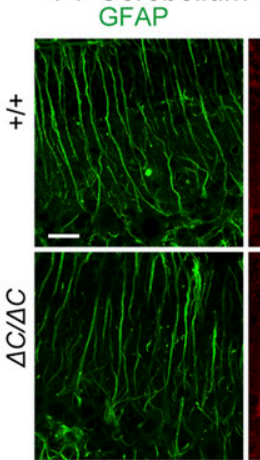

BDN

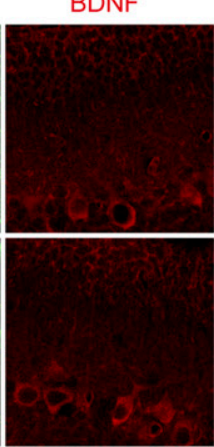

D

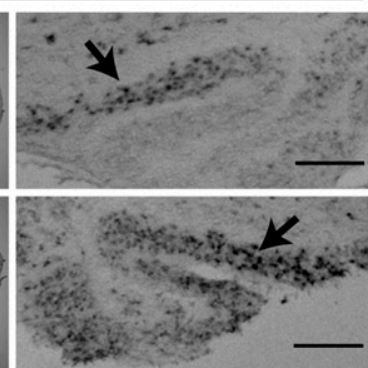

$\mathbf{F}$
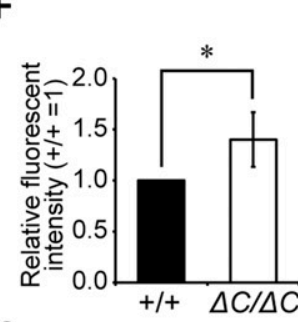

G

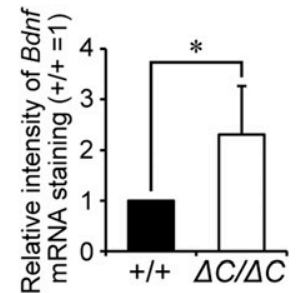

H merge+Hoechst
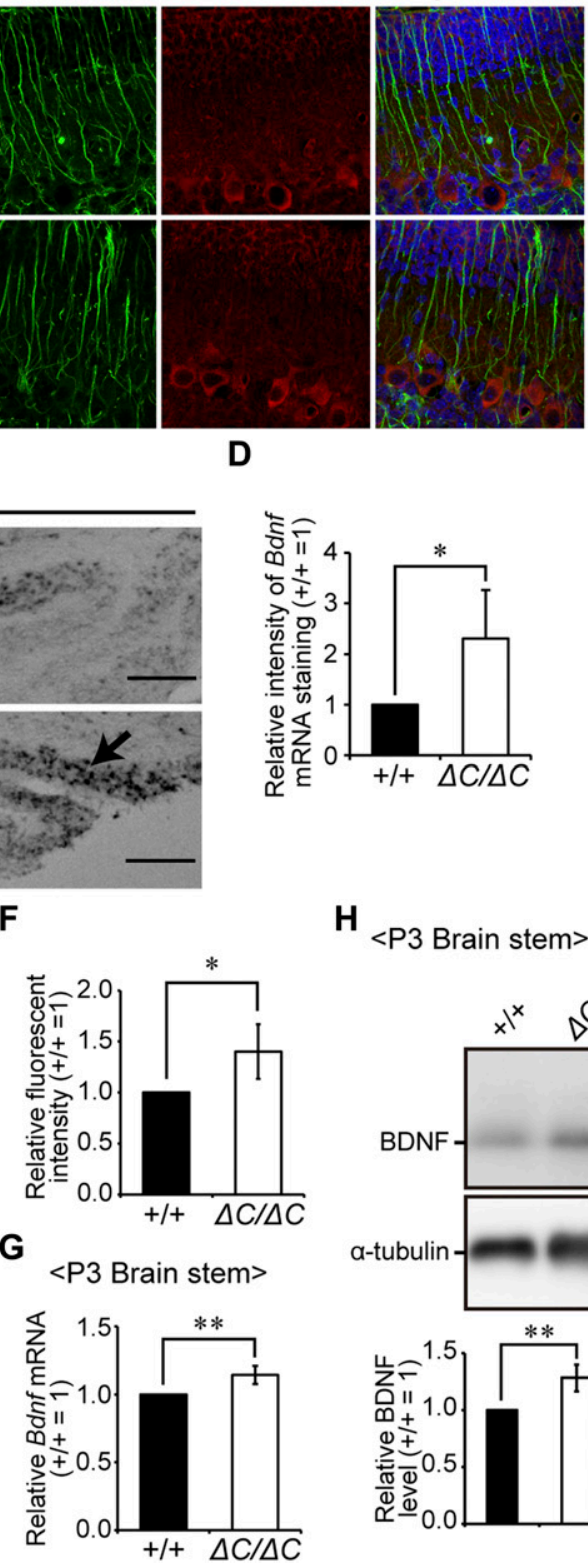

$<$ P3 Brain stem>
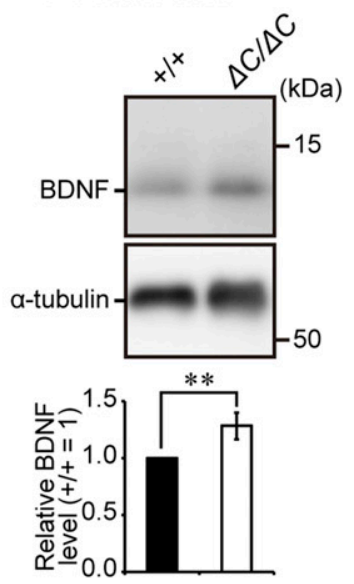

Figure 8. BDNF expression in the cerebellum and brain stem region.

(A) mRNA levels of Bdnf and Nt-4 relative to those of Rpl13a in the cerebellum from wild-type $(+/+)$ and Pex14 ${ }^{\Delta C / \Delta C}(\triangle C / \Delta C) B L / I C R$ mice at P3 were determined by real-time PCR $(n=4)$. (B) Sagittal sections of the cerebellum at P7 were stained with antibodies to GFAP (green) and BDNF (red). Merged views of the two different proteins and staining with Hoechst 33242 (blue) are shown. Scale bar, $20 \mu \mathrm{m}$. (c) In situ hybridization analysis of Bdnf mRNA in the brain stem region of wild-type (upper panels) and $P \operatorname{ex} 14^{\Delta C / \Delta C}$

(lower panels) mice at P0.5. Arrows indicate ION. Insets are higher magnification images of the dashed-line boxed regions. Scale bar, $100 \mu \mathrm{m}$. (D) Relative intensity of Bdnf mRNA staining by in situ hybridization shown in $C$ was presented $(n=3)$. (E) Sagittal sections of the brain stem at P3 were stained with anti-BDNF antibody (red) and Hoechst 33242 (blue). Scale bar, $20 \mu \mathrm{m}$. (F) Fluorescent intensity of BDNF staining on the ION shown in E was quantified $(n=3)$. (G) The mRNA level of $B d n f$ in the brain stem region was quantified by realtime PCR $(\mathrm{n}=3)$. $(\mathbf{H})$ Brain stem lysates were analyzed by SDS-PAGE and immunoblotting using antibodies against BDNF and $\alpha$-tubulin. The BDNF band was quantified (lower panel, $\mathrm{n}=4$ ). ns, not significant, ${ }^{*} P<0.05,{ }^{* *} P<0.01$, by $t$ test $(A, D, F-H)$.

Source data are available for this figure. embryo to early postnatal period. In the cortex, TrkB-TK+ was abundantly expressed and there was no difference in the expression of TrkB variants and BDNF between wild-type and Pex1 $4^{\triangle C / \Delta C}$ mice (Fig S4A-C). In addition, phosphorylation levels of ERK and AKT were not altered (Fig S4D and E). These results suggested that the BDNFTrkB signaling pathway is not responsible for the neuronal migration defect in the cortex of Pex14 $\Delta / \Delta C$ mice.

\section{Discussion}

The pathological mechanisms underlying the malformation of the CNS in patients with ZSDs are undefined. In the present study, we established a new mouse model of ZS, Pex14-defective mouse showing mild defect of peroxisomal protein import and metabolisms. At an early stage of cerebellum development in Pex $14^{\Delta C / \Delta C}$ $\mathrm{BL} / \mathrm{ICR}$ mice, the increase in BDNF together with an aberrant expression of TrkB-T1 and dysregulation of BDNF-TrkB signaling were induced. Such findings suggest that impairment in the BDNF-TrkB signaling pathway is involved in the dysmorphogenesis of the cerebellum in ZSDs.

In Pex $14^{\Delta C / \Delta C}$ mice, import of PTS1 and PTS2 proteins is partially impaired, whereas catalase import is completely defective (Fig $2 \mathrm{~A}-\mathrm{E}$ ). The targeting signal of catalase is noncanonical PTS1 sequence, KANL, instead of canonical SKL motif, at the C-terminus (Otera \& Fujiki, 2012; Purdue \& Lazarow, 1996). Binding affinity of the 
targeting signal of catalase to the cytosolic receptor, Pex $5 p$, is weaker than the canonical PTS1 proteins (Otera \& Fujiki, 2012). In addition, catalase is imported into peroxisomes as a tetrameric complex formed in the cytosol and its oligomeric import is dependent on the Pex5p-Pex13p interaction (Otera \& Fujiki, 2012). Catalase import is more susceptible to the impairment of peroxisomal matrix import than canonical PTS1 proteins, as observed in the fibroblasts from the patients with IRD, less severe ZSD (Tamura et al, 2001). In Pex14 ${ }^{\Delta C / \Delta C}$ mice, Pex14p is truncated in the C-terminal half part (Fig $1 C$ ). Because the Pex $5 p$-binding region comprising amino-acid sequence at 25 to 70 remained in Pex14p of Pex14 ${ }^{\Delta C / \Delta C}$ mouse, Pex $5 p$-cargo complex could target the surfaces of peroxisomes, giving rise to partial import of matrix proteins. Moreover, the coiled-coil domain of Pex14p is deleted in Pex $14^{\Delta C / \Delta C}$ mice. We earlier reported that the coiled-coil domain of Pex14p is required for homo-oligomerization of Pex14p (Itoh \& Fujiki, 2006). In the fibroblasts from the patient with Pex14p-Q185X mutation (Shimozawa et al, 2004), where the coiled-coil domain is truncated, catalase import is severely impaired but PTS1 import is partially affected (Fig S1). These results suggest that the coiled-coil regiondependent homo-oligomerization of Pex14p is required for the efficient import of peroxisomal matrix proteins, particularly the oligomeric import of catalase.

The Pex $14^{\Delta C / \Delta C}$ mouse shows a typical ZS phenotype, such as growth retardation, death shortly after birth, neuronal migration defects, and malformation of the cerebellum. However, the impaired peroxisome matrix protein import and peroxisomal metabolism (Fig 2) are milder than those observed in other Pex-knockout mice (Baes et al, 1997; Faust \& Hatten, 1997; Janssen et al, 2003; Maxwell et al, 2003). The metabolic abnormalities and defects in protein import in fibroblasts from a patient with a Pex14 mutation (Pex14p-Q185X) (Shimozawa et al, 2004) are similarly milder than those in fibroblasts from ZS patients (Abe et al, 2014) (Fig S1). Therefore, a mild defect in peroxisomal metabolism could also cause the severe CNS defects observed in the most severe ZS cases.

In the early stage of cerebellar development, multiple climbing fibers from the ION attach to the cell bodies of Purkinje cells. This is followed by the translocation of one climbing fiber to the dendritic tree and the establishment of climbing fiber input together with the pruning of the other climbing fibers (Sugihara, 2005; Watanabe \& Kano, 2011). Spatiotemporal BDNF-TrkB signaling is essential for the development of the cerebellum, especially in CF-PC synapse formation at an early developmental stage (Sherrard \& Bower, 2002), pruning of the CF-PC synapse (Johnson et al, 2007), and Purkinje cell arborization, as demonstrated in both types of Bdnf- (Carter et al, 2002; Schwartz et al, 1997) and TrkB-TK+- (Minichiello \& Klein, 1996; Rico et al, 2002) knockout mice. Apparent reduction of CF-PC synapse and the defect of pruning were observed in $P$ ex $14^{\Delta C / \Delta C}$ $\mathrm{BL} / \mathrm{ICR}$ mice (Figs $6 \mathrm{C}$ and S3B). The reduction of the CF-PC synapse

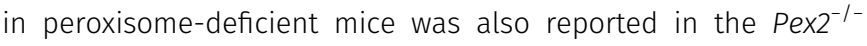
mouse cerebellum, whereas the positioning of climbing fiber to Purkinje cell layer was normal (Faust, 2003). These results imply the impaired maturation of CF-PC synapse. It is conceivable that TrkB$\mathrm{TK}+$ is located on the post-synaptic compartment of the dendritic spine and is involved in synapse formation and stabilization (Yoshii \& Constantine-Paton, 2010). In addition, BDNF-TrkB activity is thought to be involved in the promotion and stabilization of CF-PC synaptic formation (Sherrard et al, 2009). Thus, severe reduction of TrkB-positive punctate structures in Pex $14^{\Delta C / \Delta C}$ BL/ICR mice (Fig 6A and $B$ ) could be explained by the excess TrkB-T1 that affects the expression of TrkB-TK+ at the cell surface (Haapasalo et al, 2002), thereby suppressing the phosphorylation of TrkB-TK+ and its downstream signaling targets, ERK and AKT (Fig 7). Based on these findings, it is most likely that the disturbance of the BDNF-TrkB signaling pathway in the cerebellum is involved in the impairment in CF-PC synapse maturation.

In the developmental stage of the cerebellum, BDNF immunoreactivity is evident around Purkinje cells (Schwartz et al, 1997), whereas expression of Bdnf mRNA is undetectable using either Northern blot analysis (Maisonpierre et al, 1990) or in situ hybridization (Rocamora et al, 1993). Therefore, the BDNF protein in the Purkinje cell layer is thought to be delivered via climbing fibers from the ION (Lindholm et al, 1997; Sherrard \& Bower, 2002), where Bdnf mRNA is strongly expressed at the stage of climbing fiber growth and synaptogenesis (Rocamora et al, 1993). Indeed, the expression of Bdnf mRNA is up-regulated in the ION neurons of Pex $14^{\Delta C / \Delta C}$ mice (Fig $\left.8 C-H\right)$. However, it remains undefined how the elevation of Bdnf mRNA is regulated in the peroxisome-deficient ION neurons. Further studies would be required to elucidate the molecular mechanisms underlying the transcriptional upregulation of the Bdnf gene in the ION of Pex-knockout mice.

In Pex $14^{\Delta C / \Delta C} B L / I C R$ mouse cerebellum, Purkinje cells show axonal swelling and growth defects of dendrites. These defects of neuronal morphogenesis in the cerebellum of $\operatorname{Pex} 14^{\Delta C / \Delta C}$ mice are likely explained by the impaired spatiotemporal BDNF-TrkB signaling pathway apparently induced by excess BDNF, not NT-4 (Fig 8A), and enhanced expression of TrkB-T1 (Fig 6E and G). Indeed, in the primary culture of cerebellar neurons, the dendritic development of Purkinje cells from Pex $14^{\Delta C / \Delta C} B L / I C R$ mice was compromised (Fig $5 \mathrm{G}$ and $\mathrm{H}$ ) and swollen axons were increased by the BDNF treatment (Fig 5C and F). The defect of dendritic arborization in primary Purkinje cells is in good agreement with the notion that excess BDNF inhibits the dendritic growth of the cells expressing TrkB-T1 via the dominant-negative inhibition of TrkB-TK+ signaling (Fenner, 2012; Yacoubian \& Lo, 2000), although the downstream of the BDNF signaling pathway of dendritic abnormality and its relationship to the signaling for axonal swelling remain unclear. There is no effect of BDNF on the wild-type Purkinje cells in the primary culture of cerebellar cells (Fig 5), consistent with the finding that BDNF-transgenic mice show no significant difference of cerebellar morphology (Bao et al, 1999). Therefore, the malformation of Purkinje cells in Pex $14^{\Delta C / \Delta C} B L / I C R$ mice is most likely caused by a combination of elevated BDNF and prominent expression of TrkB-T1 (Fig S5). The findings in the in vitro assay of primary cerebellar neurons could also exclude the possibility that only growth retardation caused by the deficiency of peroxisomal functions in liver compromises the maturation of the cerebellum (Krysko et al, 2007).

The molecular mechanism underlying the alternative splicing of the TrkB-T1 variant remains elusive. In the Pex $14^{\Delta C / \Delta C} \mathrm{BL} /$ ICR mouse cerebellum, TrkB-T1 expression is up-regulated and phosphorylation of TrkB-TK+, ERK, and AKT is down-regulated, suggesting the inhibition of TrkB-TK+-elicited signal transduction. The upregulation of TrkB-T1 is less likely dependent on the elevation of 
BDNF in Pex $14^{\Delta C / \Delta C}$ BL/ICR mice because BDNF treatment did not alter the TrkB-T1 expression in the primary neuron (Fig S3C and D). In addition, the BDNF transgenic mouse shows normal cerebellar development (Bao et al, 1999), suggesting that excess BDNF is irrelevant to up-regulation of TrkB-T1 (Bao et al, 1999). The elevation of mRNA for TrkB-T1 in the Pex14 ${ }^{\Delta C / \Delta C} B L / I C R$ mouse cerebellum suggests that TrkB mRNA splicing is affected by the defect in peroxisomal biogenesis. Therefore, molecular mechanisms addressing the issue of how peroxisomal dysfunction affects the splicing of TrkB in Purkinje cells will shed light on understanding the malformation of the cerebellum in PBDs.

In the cerebellum of patients with ZS, dysmorphology of the Purkinje cell arborization, heterotopia of Purkinje cells in the white matter, and granule cell clustering between the Purkinje cells are observed (Volpe \& Adams, 1972; de León et al, 1977; Evrard et al, 1978; Powers \& Moser, 1998; Crane, 2014). These phenotypes resemble those in Pex-knockout mice, including the impairment of Purkinje cell arborization and granule cell migration defect, although the heterotopic Purkinje cells are much less severe (Faust \& Hatten, 1997; Faust, 2003). During cerebellar development, the BDNF-TrkB signaling pathway plays pivotal roles in Purkinje cell arborization (Minichiello \& Klein, 1996; Schwartz et al, 1997; Carter et al, 2002; Rico et al, 2002) and in granule cell migration from the external granular layer to the IGL (Zhou et al, 2007). Heterotopic Purkinje cells are also observed in the patients with milder ZSDs, NALD, and IRD (Aubourg et al, 1986; Torvik et al, 1988; Chow et al, 1992). Therefore, the BDNFTrkB signaling pathway in the cerebellum is most likely susceptible to the impaired peroxisomal metabolism in ZSDs, including ZS, NALD, and IRD.

\section{Materials and Methods}

\section{Construction of a targeting vector and generation of $P \operatorname{ex} 14^{\Delta C / \Delta C}$ mice}

Genomic DNA corresponding to the Pex14 locus was isolated from 129/Sv mouse genomic library (Agilent Technologies). The targeting vector was constructed by replacing a 6.5-kb Sacl-AorH51I fragment of genomic DNA containing three Pex14 exons, exons 6-8, with a PGK-lox-neo-poly (A) cassette. The vector thus contained 1.7- and 6.0-kb regions of homology located $5^{\prime}$ and $3^{\prime}$, respectively, relative to the neomycin resistance gene (Neor). A MC1-DT-A-poly (A) cassette was ligated at the $3^{\prime}$ end of the targeting construct. The maintenance, transfection, and selection of ES cells derived from $129 /$ Sv mice were carried out as described previously (Nakayama et al, 1996). Mutant ES cells were microinjected into C57BL/ 6 mouse blastocysts, and the resulting male chimeras were mated with C57BL/ 6 females. Germ line transmission of the mutant allele was confirmed by Southern blot analysis. Heterozygous offspring were intercrossed to produce homozygous mutant animals. PCR analysis of tail biopsy genomic DNA was undertaken using primers P14F (5' GTATAAATGTGGGAGTTTCCCTGG-3') and P14R (5'-GTACTTGTGAACTCTGCTGGTAC-3') to amplify a 599-bp fragment specific for the wild-type allele and primers P14F and KN52-2 (5'-GTGTTGGGTCGTTTGTTCGG-3') to amplify a 169-bp fragment specific for the disrupted Pex14 gene.

\section{Antibodies and plasmids}

Mouse monoclonal antibodies against calbindin- $D_{28 k}(C B-955)$ and GFAP (G-A-5) were purchased from sigma-Aldrich, and mouse monoclonal antibody to $\alpha$-tubulin was from BD Biosciences. Rabbit antibodies to BDNF (N-20) and TrkB ( $\mathrm{H}-181)$ and mouse antibody to phosphorylated Trk (Y496, E-6) were from Santa Cruz Biotechnology. Mouse monoclonal antibodies against Tuj-1 and ERK1/2 and rabbit antibody to phospho-ERK1/2 were from R\&D systems. Rabbit antibodies to AKT (N3C2), phosphor-AKT (S473), PLCY, and phosphorPLCY (Y783) were from GeneTex. Guinea pig antibody to vGlut2 and goat antibody to lactate dehydrogenase (LDH) were from Millipore and Rockland, respectively. We used rabbit antisera against PTS1 peptides (Otera et al, 1998), rat AOx (Tsukamoto et al, 1990), human catalase (Shimozawa et al, 1992), rat catalase (Tsukamoto et al, 1990), mouse ADAPS (Honsho et al, 2008), rat 70-kD peroxisomal integral membrane protein (PMP70) (Tsukamoto et al, 1990), Chinese hamster Pex5p (Otera et al, 2000), and the carboxyl terminal part of rat Pex14p (Pex14pC) (Shimizu et al, 1999). Rabbit antibody raised to amino-terminal 106 amino acid residues of rat Pex14p (Pex14pN) (Okumoto et al, 2000; Itoh \& Fujiki, 2006) was also used. The p75ECD plasmid coding for the amino-acid sequence at 1-747 was ligated into the HindIII-Xhol sites of pSecTag2/Hygro C vector (Invitrogen), yielding pSecTag2/p75ECD-His.

\section{Cell culture}

CHO K1 cells were cultured in Ham's F12 medium (Invitrogen) containing $10 \%$ FBS. SH-SY5Y from the Human Science Research Resources Bank and fibroblasts from a control and a patient with PEX14 mutation (K01) (Shimozawa et al, 2004) were cultured in DMEM (Invitrogen) supplemented with 10\% FBS. Transfection of pSecTag2/p75ECD-His to CHO-K1 was carried out with Lipofectamine (Invitrogen) according to the manufacturer's instructions. Stable transformants of $\mathrm{CHO}$ K1 cells were isolated by selection with $1.2 \mu \mathrm{g} / \mathrm{ml}$ hygromycin (Sigma-Aldrich). For siRNA transfection, SHSY5Y cells $\left(2 \times 10^{5}\right)$ were transfected with 5 pmol dsRNA using Lipofectamine RNAiMAX (Invitrogen) and plated on poly-L-lysine (Sigma-Aldrich)-coated cover glasses. The sequences siRNA used were as follows: PEX5 \#1, 5'-UAAUAGUUCUUGUUCAUUCUCUGCC-3' and 5'-GGCAGAGAAUGAACAAGAACUAUUA-3'; PEX5 \#2, 5'-UUUAGCUCCAGACACCUCCGCAAUG-3' and 5'-CAUUGCGGAGGUGUCUGGAGCUAAA-3'. Cells were cultured for $2 \mathrm{~d}$ and stained with antibodies to Tuj-1 and Hoechst 33242.

\section{Primary culture of cerebellar neurons}

Primary cerebellar neurons were prepared from a mouse at P0.5. Briefly, cerebella were excised into small pieces and dissociated with 15 units of papain (Worthington Biochemical Corporation) in dissociation solutions $(0.2 \mathrm{mg} / \mathrm{ml}$ L-cysteine, $0.2 \mathrm{mg} / \mathrm{ml} \mathrm{BSA}$, and $10 \mathrm{mg} / \mathrm{ml}$ glucose) and $0.1 \mathrm{mg} / \mathrm{ml}$ DNase I (Sigma-Aldrich). Cells were separated by gentle trituration passes using a 10-ml pipette and were passed through a 70- $\mu \mathrm{m}$ cell strainer (BD Biosciences) to remove large debris. Dissociated cerebellar cells $\left(3.0 \times 10^{5}\right.$ cells $/ \mathrm{cm}^{2}$ ) were plated at $37^{\circ} \mathrm{C}$ under $5 \% \mathrm{CO}_{2}$ on poly-L-lysine- and laminin (Sigma-Aldrich)-coated cover glasses in Neurobasal 
medium (Invitrogen) containing B27 supplement (Invitrogen) and $0.5 \mathrm{mM}$ L-glutamine. Culture medium was replaced with fresh medium every 3-4 d. Purkinje cells were stained with anticalbindin- $\mathrm{D}_{28 \mathrm{k}}$ antibody and observed by an AF 6000LX microscope (Leica). The areas of cell body and dendrites of Purkinje cells were measured by Image J software (National Institutes of Health).

\section{Purification of p75ECD-His}

A stable transformant of $\mathrm{CHO} \mathrm{K} 1$ cell expressing p75ECD-His was cultured in serum-free F12 medium for $3 \mathrm{~d}$. The cell cultured medium was collected and centrifuged to remove floating cells. The resulting supernatant fraction was mixed and incubated with $\mathrm{Ni}-$ NTA agarose beads (QIAGEN) for $4 \mathrm{~h}$. The p75ECD-His-bound beads were washed 6 times with purification buffer (50 mM Hepes- $\mathrm{KOH}$, pH 7.4, $150 \mathrm{mM} \mathrm{NaCl}, 20 \mathrm{mM}$ imidazole, and 10\% glycerol) followed by elution with purification buffer containing $250 \mathrm{mM}$ imidazole. The eluent was loaded onto a PD10 column (GE Healthcare) with suspension buffer (50 mM Hepes- $\mathrm{KOH}, \mathrm{pH} 7.4,150 \mathrm{mM} \mathrm{NaCl}$, and 10\% glycerol) and then concentrated by ultrafiltration in an Amicon Ultra-15 (10,000 molecular weight cut-off; Millipore). Purified p75ECD-His was added to the cell culture at $1.0 \mu \mathrm{g} / \mathrm{ml}$.

\section{Lipid extraction}

Cells were detached from culture plates by incubation with trypsin and suspended in PBS. Protein concentration was determined by the bicinchonic acid method (Thermo Fisher Scientific). Total lipids were extracted from $50 \mu \mathrm{g}$ of total cellular proteins by the Bligh and Dyer method (Bligh \& Dyer, 1959). Cells were suspended in methanol/chloroform/water at 2:1:0.8 (vol/ $\mathrm{vol} / \mathrm{vol}$ ) and then $50 \mathrm{pmol}$ of 1-heptadecanoyl-sn-glycero3-phosphocholine (LPC; Avanti Polar Lipids), 1, 2-didodecanoyl-sn-glycero-3-phosphocholine (DDPC; Avanti Polar Lipids), and 1, 2-didodecanoyl-sn-glycero-3-phosphoethanolamine (DDPE; Avanti Polar Lipids) were added as internal standards. After incubation for $5 \mathrm{~min}$ at room temperature, $1 \mathrm{ml}$ each of water and chloroform was added and the samples were then centrifuged at $720 \mathrm{~g}$ for $5 \mathrm{~min}$ in Himac CF-16RX (Hitachi Koki) to collect the lower organic phase. To reextract lipids from the water phase, $1 \mathrm{ml}$ chloroform was added. The combined organic phase was evaporated under a nitrogen stream and the extracted lipids were dissolved in methanol.

\section{Liquid chromatography coupled with tandem mass spectrometry (LC-MS/MS)}

LC-MS/MS was performed as described (Abe et al, 2014) using a 4000 Q-TRAP quadrupole linear ion trap hybrid mass spectrometer (AB Sciex) with an ACQUITY UPLC system (Waters). The data were analyzed and quantified using Analyst software (AB Sciex).

\section{Real-time RT-PCR}

Total RNA was extracted from cells using TRIzol reagent (Invitrogen) and first-strand cDNA was synthesized by the PrimeScript RT reagent Kit (Takara Bio). Quantitative real-time RT-PCR was performed with SYBR Premix Ex Taq II (Takara Bio) using an Mx3000P QPCR system (Agilent Technologies). Several sets of primers used are listed in Table S1.

\section{Immunofluorescent microscopy}

Cultured cells were fixed with $4 \%$ paraformaldehyde in PBS, $\mathrm{pH} 7.4$, for $15 \mathrm{~min}$ at room temperature. Peroxisomes were visualized by indirect immunofluorescence staining with indicated antibodies as described previously (Mukai et al, 2002). Antigen-antibody complexes were detected with goat anti-mouse and anti-rabbit IgG conjugated to Alexa Fluor 488 and Alexa Fluor 568 (Invitrogen). Phalloidin-TRITC (Sigma-Aldrich) was used for the staining of F-actin. Images were obtained using a laser-scanning confocal microscope (LSM 710 with Axio Observer.Z1; Carl Zeiss).

\section{Immunohistochemistry}

Neonatal mice were deeply anesthetized with isoflurane and perfused transcardially with $1 \mathrm{ml}$ of $4 \%$ PFA in $0.1 \mathrm{M}$ phosphate buffer (PB). After decapitation, the brains were fixed in the same buffer overnight at $4^{\circ} \mathrm{C}$ and were transferred to $30 \%$ sucrose in PBS for $2 \mathrm{~d}$. The brains were embedded in the Tissue-Tek OCT compound (Sakura Finetek) and subsequently frozen at $-80^{\circ} \mathrm{C}$. Cryosections were cut at a thickness of $20 \mu \mathrm{m}$ using a cryostat Microm HM550-OMP (Thermo Fisher Scientific) and were then mounted on MAS-coated glass slides (Matsunami Glass). The sections were permeabilized by ice-cold methanol, blocked by blocking buffer (10\% BSA, 0.3\% Triton X-100 in PBS), and then incubated overnight at $4^{\circ} \mathrm{C}$ with primary antibody diluted in blocking buffer or Can Get Signal immunostain solution A (Toyobo). After washing with PBS, the sections were incubated with appropriate secondary antibody conjugated to Alexa 488 or 567; for marker staining of nuclei, the sections were incubated with Hoechst 33242 in PBS for 2 min at room temperature, and then mounted with PermaFluor. Images were obtained under an LSM 710, AF 6000LX, or BZ-9000 (Keyence) microscope. Quantitative analysis was performed by BZII-analyzer (Keyence).

\section{Immunoblotting}

Immunoblotting was performed as previously described (Honsho et al, 2015). Precision Plus Protein All Blue standards (Bio-Rad) were used as molecular size markers. Immunoblots were developed with ECL prime reagent (GE Healthcare) and immunoreactive bands were detected by X-ray film (GE Healthcare) or LAS-4000 Mini luminescent image analyzer (Fujifilm). The band intensities were quantified by Image I software or Image Gauge software (Fujifilm).

\section{In situ hybridization}

Brains were removed, fixed overnight in $4 \%$ PFA in $0.1 \mathrm{M} \mathrm{PB}$, incubated another overnight in 30\% sucrose / $4 \%$ PFA in $0.1 \mathrm{M} \mathrm{PB}$, and sectioned at $20 \mu \mathrm{m}$ by a cryostat, as previously described (Ueno et al, 2012). Digoxigenin-labeled riboprobes were prepared by in vitro transcription. Sections were hybridized with digoxigeninlabeled probe at $70^{\circ} \mathrm{C}$ overnight. Excess probes were washed out and signals were detected with alkaline phosphatase-coupled 
antibody to digoxigenin (Roche Diagnostics) with nitroblue tetrazolium and 5-bromo-4-chloro-3-indolyl phosphate as color reaction substrates.

\section{Statistical analysis}

Statistical analysis was performed using R software (http://www. $r$-project.org). All $t$ tests used were one-tailed. A $P$ value $<0.05$ was considered statistically significant. Data are shown as means \pm SD unless otherwise described.

\section{Study approval}

The animal ethics committee of Kyushu University approved all animal experiments.

\section{Supplementary Information}

Supplementary Information is available at https://doi.org/10.26508/lsa. 201800062.

\section{Acknowledgments}

We thank R.J.A. Wanders for providing fibroblasts from a patient with PEX14 mutation. We also thank Y Nanri and S Okuno for technical assistance, K Shimizu for preparing the figures, and the other members of our laboratory for helpful discussion. We appreciate the technical assistance from The Research Support Center, Research Center for Human Disease Modeling, Kyushu University Graduate School of Medical Sciences and Laboratory for Technical Support, Medical Institute of Bioregulation, Kyushu University. This work was supported in part by grants from the Ministry of Education, Culture, Sports, Science, and Technology of Japan; Grants-in-Aid for Scientific Research (no. JP17K15621 to Y Abe; nos. JP24247038, JP25112518, JP25116717, JP26116007, JP15K14511, JP15K21743, and JP17H03675 to Y Fujiki); grants from the Takeda Science Foundation (to Y Fujiki), the Naito Foundation (to Y Fujiki), the Japan Foundation for Applied Enzymology, and the Novartis Foundation (Japan) for the Promotion of Science (to Y Fujiki).

\section{Author Contributions}

Y Abe: conceptualization, resources, data curation, formal analysis, funding acquisition, validation, investigation, visualization, methodology, project administration, and writing-original draft. M Honsho: conceptualization, resources, data curation, investigation, visualization, project administration, and writing-original draft.

$\mathrm{R}$ Itoh: resources and formal analysis.

R Kawaguchi: formal analysis.

M Fujitani: resources, formal analysis, validation, and investigation. K Fujiwara: formal analysis.

M Hirokane: formal analysis.

T Matsuzaki: formal analysis and methodology.

K Nakayama: resources, formal analysis, and methodology.

R Ohgi: formal analysis.

T Marutani: resources and formal analysis.

KI Nakayama: resources, formal analysis, and methodology.

T Yamashita: resources, formal analysis, and methodology.
Y Fujiki: conceptualization, resources, data curation, supervision, funding acquisition, investigation, project administration, and writing-original draft, review, and editing.

\section{Conflict of Interest Statement}

The authors declare no competing financial interests.

\section{References}

Abe Y, Honsho M, Nakanishi H, Taguchi R, Fujiki Y (2014) Very-long-chain polyunsaturated fatty acids accumulate in phosphatidylcholine of fibroblasts from patients with Zellweger syndrome and acyl-CoA oxidase1 deficiency. Biochim Biophys Acta 1841: 610-619. doi:10.1016/j. bbalip.2014.01.001

Aubourg P, Scotto J, Rocchiccioli F, Feldmann-Pautrat D, Robain O (1986) Neonatal adrenoleukodystrophy. J Neurol Neurosurg Psychiatry 49: 77-86. doi:10.1136/jnnp.49.1.77

Baes M, Gressens P, Baumgart E, Carmeliet P, Casteels M, Fransen M, Evrard P Fahimi D, Declercq PE, Collen D, et al (1997) A mouse model for Zellweger syndrome. Nat Genet 17: 49-57. doi:10.1038/ng0997-49

Bao S, Chen L, Qiao X, Thompson RF (1999) Transgenic brain-derived neurotrophic factor modulates a developing cerebellar inhibitory synapse. Learn Mem 6: 276-283. doi:10.1101/lm.6.3.276

Baranowska-Bosiacka I, Struzynska L, Gutowska I, Machalinska A, Kolasa A, Klos P, Czapski GA, Kurzawski M, Prokopowicz A, Marchlewicz M, et al (2013) Perinatal exposure to lead induces morphological, ultrastructural and molecular alterations in the hippocampus Toxicology 303: 187-200. doi:10.1016/j.tox.2012.10.027

Barøy T, Koster J, Strømme P, Ebberink MS, Misceo D, Ferdinandusse S, Holmgren A, Hughes T, Merckoll E, Westvik J, et al (2015) A novel type of rhizomelic chondrodysplasia punctata, RCDP5, is caused by loss of the PEX5 long isoform. Hum Mol Genet 24: 5845-5854. doi:10.1093/hmg/ ddv305

Bligh EG, Dyer WJ (1959) A rapid method of total lipid extraction and purification. Can J Biochem Physiol 37: 911-917. doi:10.1139/059-099

Bottelbergs A, Verheijden S, Hulshagen L, Gutmann DH, Goebbels S, Nave K-A Kassmann C, Baes M (2010) Axonal integrity in the absence of functional peroxisomes from projection neurons and astrocytes. Glia 58: 1532-1543. doi:10.1002/glia.21027

Braverman N, Steel G, Obie C, Moser A, Moser H, Gould SJ, Valle D (1997) Human PEX7 encodes the peroxisomal PTS2 receptor and is responsible for rhizomelic chondrodysplasia punctata. Nat Genet 15: 369-376. doi:10.1038/ng0497-369

Carter AR, Chen C, Schwartz PM, Segal RA (2002) Brain-derived neurotrophic factor modulates cerebellar plasticity and synaptic ultrastructure. J Neurosci 22: 1316-1327. doi:10.1523/jneurosci.22-04-01316.2002

Chow CW, Poulos A, Fellenberg AJ, Christodoulou J, Danks DM (1992) Autopsy findings in two siblings with infantile Refsum disease. Acta Neuropathol 83: 190-195. doi:10.1007/bf00308478

Crane DI (2014) Revisiting the neuropathogenesis of Zellweger syndrome. Neurochem Int 69: 1-8. doi:10.1016/j.neuint.2014.02.007

de León GA, Grover WD, Huff DS, Morinigo-Mestre G, Punnett HH, Kistenmacher ML (1977) Globoid cells, glial nodules, and peculiar fibrillary changes in the cerebro-hepato-renal syndrome of Zellweger. Ann Neurol 2: 473-484. doi:10.1002/ana.410020606

Eide FF, Vining ER, Eide BL, Zang K, Wang X-Y, Reichardt LF (1996) Naturally occurring truncated trkB receptors have dominant inhibitory effects 
on brain-derived neurotrophic factor signaling. J Neurosci 16 3123-3129. doi:10.1523/jneurosci.16-10-03123.1996

Evrard P, Caviness VSJ, Prats-Vinas J, Lyon G (1978) The mechanism of arrest of neuronal migration in the Zellweger malformation: An hypothesis bases upon cytoarchitectonic analysis. Acta Neuropathol 41: 109-117. doi:10.1007/bf00689761

Faust PL (2003) Abnormal cerebellar histogenesis in PEX2 Zellweger mice reflects multiple neuronal defects induced by peroxisome deficiency. J Comp Neurol 461: 394-413. doi:10.1002/cne.10699

Faust PL, Hatten ME (1997) Targeted deletion of the PEX2 peroxisome assembly gene in mice provides a model for Zellweger syndrome, a human neuronal migration disorder. J Cell Biol 139: 1293-1305. doi:10.1083/jcb.139.5.1293

Faust PL, Su HM, Moser A, Moser HW (2001) The peroxisome deficient PEX2 Zellweger mouse: Pathogenic and biochemical correlates of lipid dysfunction. J Mol Neurosci 16: 289-297. doi:10.1385/jmn:16: 2-3:289

Fenner BM (2012) Truncated TrkB: Beyond a dominant negative receptor. Cytokine Growth Factor Rev 23: 15-24. doi:10.1016/j.cytogfr.2012.01.002

Friedman WJ, Black IB, Kaplan DR (1998) Distribution of the neurotrophins brain-derived neurotrophic factor, neurotrophin-3, and neurotrophin-4/5 in the postnatal rat brain: An immunocytochemical study. Neuroscience 84: 101-114. doi:10.1016/s0306-4522(97)00526-5

Fryer RH, Kaplan DR, Kromer LF. (1997) Truncated trkB receptors on nonneuronal cells inhibit BDNF-induced neurite outgrowth in vitro. Exp Neurol 148: 616-627. doi:10.1006/exnr.1997.6699

Fujiki Y (2016) Peroxisome biogenesis and human peroxisome-deficiency disorders. Proc Jpn Acad Ser B Phys Biol Sci 92: 463-477. doi:10.2183/ pjab.92.463

Fujiki Y, Okumoto K, Mukai S, Honsho M, Tamura S (2014) Peroxisome biogenesis in mammalian cells. Front Physiol 5: 307. doi:10.3389/ fphys.2014.00307

Haapasalo A, Sipola I, Larsson K, Akerman KE, Stoilov P, Stamm S, Wong G, Castren E (2002) Regulation of TRKB surface expression by brainderived neurotrophic factor and truncated TRKB isoforms. J Biol Chem 277: 43160-43167. doi:10.1074/jbc.m205202200

Honsho M, Abe Y, Fujiki Y (2015) Dysregulation of plasmalogen homeostasis impairs cholesterol biosynthesis. J Biol Chem 290: 28822-28833. doi:10.1074/jbc.m115.656983

Honsho M, Yagita Y, Kinoshita N, Fujiki Y (2008) Isolation and characterization of mutant animal cell line defective in alkyl-dihydroxyacetonephosphate synthase: Localization and transport of plasmalogens to post-Golgi compartments. Biochim Biophys Acta 1783: 1857-1865. doi:10.1016/j. bbamcr.2008.05.018

Itoh R, Fujiki Y (2006) Functional domains and dynamic assembly of the peroxin Pex14p, the entry site of matrix proteins. J Biol Chem 281: 10196-10205. doi:10.1074/jbc.m600158200

Janssen A, Gressens P, Grabenbauer M, Baumgart E, Schad A, Vanhorebeek I, Brouwers A, Declercq PE, Fahimi D, Evrard P, et al (2003) Neuronal migration depends on intact peroxisomal function in brain and in extraneuronal tissues. J Neurosci 23: 9732-9741. doi:10.1523/ jneurosci.23-30-09732.2003

Johnson EM, Craig ET, Yeh HH (2007) TrkB is necessary for pruning at the climbing fibre-Purkinje cell synapse in the developing murine cerebellum. J Physiol 582: 629-646. doi:10.1113/jphysiol.2007.133561

Kaplan DR, Matsumoto K, Lucarelli E, Thiele CJ (1993) Induction of TrkB by retinoic acid mediates biologic responsiveness to BDNF and differentiation of human neuroblastoma cells. Eukaryotic Signal Transduction Group. Neuron 11: 321-331. doi:10.1016/0896-6273(93) $90187-\mathrm{V}$

Kassmann CM, Lappe-Siefke C, Baes M, Brügger B, Mildner A, Werner HB, Natt O, Michaelis T, Prinz M, Frahm J, et al (2007) Axonal loss and neuroinflammation caused by peroxisome-deficient oligodendrocytes. Nat Genet 39: 969-976. doi:10.1038/ng2070

Klein R, Conway D, Parada LF, Barbacid M (1990) The trkB tyrosine protein kinase gene codes for a second neurogenic receptor that lacks the catalytic kinase domain. Cell 61: 647-656. doi:10.1016/0092-8674(90) 90476-u

Krysko O, Hulshagen L, Janssen A, Schütz G, Klein R, De Bruycker M, Espeel M, Gressens P, Baes M (2007) Neocortical and cerebellar developmental abnormalities in conditions of selective elimination of peroxisomes from brain or from liver. J Neurosci Res 85: 58-72. doi:10.1002/jnr.21097

Lindholm D, Hamnér S, Zirrgiebel U (1997) Neurotrophins and cerebellar development. Perspect Dev Neurobiol 5: 83-94.

Maisonpierre PC, Belluscio L, Friedman B, Alderson RF, Wiegand SJ, Furth ME, Lindsay RM, Yancopoulos GD (1990) NT-3, BDNF, and NGF in the developing rat nervous system: Parallel as well as reciprocal patterns of expression. Neuron 5: 501-509. doi:10.1016/0896-6273(90)90089-x

Maxwell M, Bjorkman J, Nguyen T, Sharp P, Finnie J, Paterson C, Tonks I, Paton BC, Kay GF, Crane DI (2003) Pex13 inactivation in the mouse disrupts peroxisome biogenesis and leads to a Zellweger syndrome phenotype. Mol Cell Biol 23: 5947-5957. doi:10.1128/mcb.23.16.59475957.2003

Medina DL, Sciarretta C, Calella AM, Von Bohlen Und Halbach O, Unsicker K, Minichiello L (2004) TrkB regulates neocortex formation through the Shc/PLCY-mediated control of neuronal migration. EMBO / 23: 3803-3814. doi:10.1038/sj.emboj.7600399

Minichiello L, Klein R (1996) TrkB and TrkC neurotrophin receptors cooperate in promoting survival of hippocampal and cerebellar granule neurons. Genes Dev 10: 2849-2858. doi:10.1101/gad.10.22.2849

Miyazawa S, Osumi T, Hashimoto T, Ohno K, Miura S, Fujiki Y (1989) Peroxisome targeting signal of rat liver acyl-coenzyme A oxidase resides at the carboxy terminus. Mol Cell Biol 9: 83-91. doi:10.1128/ mcb.9.1.83

Motley AM, Hettema EH, Hogenhout EM, Brites P, ten Asbroek ALMA, Wijburg FA, Baas F, Heijmans HS, Tabak HF, Wanders RJA, et al (1997) Rhizomelic chondrodysplasia punctata is a peroxisomal protein targeting disease caused by a non-functional PTS2 receptor. Nat Genet 15: 377-380. doi:10.1038/ng0497-377

Mukai S, Ghaedi K, Fujiki Y (2002) Intracellular localization, function, and dysfunction of the peroxisome-targeting signal type 2 receptor, Pex7p, in mammalian cells. J Biol Chem 277: 9548-9561. doi:10.1074/jbc. m108635200

Müller CC, Nguyen TH, Ahlemeyer B, Meshram M, Santrampurwala N, Cao S, Sharp P, Fietz PB, Baumgart-Vogt E, Crane DI (2011) PEX13 deficiency in mouse brain as a model of Zellweger syndrome: Abnormal cerebellum formation, reactive gliosis and oxidative stress. Dis Model Mech 4: 104-119. doi:10.1242/dmm.004622

Nakayama K, Ishida N, Shirane M, Inomata A, Inoue T, Shishido N, Horii I, Loh DY, Nakayama K (1996) Mice lacking p27 ${ }^{\text {Kip } 1}$ display increased body size, multiple organ hyperplasia, retinal dysplasia, and pituitary tumors. Cell 85: 707-720. doi:10.1016/s0092-8674(00)81237-4

Numakawa T, Suzuki S, Kumamaru E, Adachi N, Richards M, Kunugi H (2010) BDNF function and intracellular signaling in neurons. Histol Histopathol 25: 237-258. doi:10.14670/HH-25.237

Okumoto K, Abe I, Fujiki Y (2000) Molecular anatomy of the peroxin Pex12p: RING finger domain is essential for Pex $12 p$ function and interacts with the peroxisome-targeting signal type 1-receptor Pex5p and a RING peroxin, Pex10p. J Biol Chem 275: 25700-25710. doi:10.1074/jbc. m003303200

Otera H, Fujiki Y (2012) Pex5p imports folded tetrameric catalase by interaction with Pex13p. Traffic 13: 1364-1377. doi:10.1111/j.16000854.2012.01391.x

Otera H, Harano T, Honsho M, Ghaedi K, Mukai S, Tanaka A, Kawai A, Shimizu N, Fujiki Y (2000) The mammalian peroxin Pex5pL, the longer isoform of 
the mobile peroxisome targeting signal (PTS) type 1 transporter, translocates Pex7p-PTS2 protein complex into peroxisomes via its initial docking site, Pex14p. J Biol Chem 275: 21703-21714. doi:10.1074/ jbc.m000720200

Otera H, Okumoto K, Tateishi K, Ikoma Y, Matsuda E, Nishimura M, Tsukamoto T, Osumi T, Ohashi K, Higuchi O, et al (1998) Peroxisome targeting signal type 1 (PTS1) receptor is involved in import of both PTS1 and PTS2: Studies with PEX5-defective CHO cell mutants. Mol Cell Biol 18: 388-399. doi:10.1128/mcb.18.1.388

Powers JM, Moser HW (1998) Peroxisomal disorders: Genotype, phenotype, major neuropathologic lesions, and pathogenesis. Brain Pathol 8: 101-120. doi:10.1111/j.1750-3639.1998.tb00139.x

Purdue PE, Lazarow PB (1996) Targeting of human catalase to peroxisomes is dependent upon a novel $\mathrm{COOH}$-terminal peroxisomal targeting sequence. J Cell Biol 134: 849-862. doi:10.1083/jcb.134.4.849

Purdue PE, Zhang JW, Skoneczny M, Lazarow PB (1997) Rhizomelic chondrodysplasia punctata is caused by deficiency of human PEX7, a homologue of the yeast PTS2 receptor. Nat Genet 15: 381-384. doi:10.1038/ng0497-381

Reichardt LF (2006) Neurotrophin-regulated signalling pathways. Philos Trans R Soc Lond B Biol Sci 361: 1545-1564. doi:10.1098/rstb.2006.1894

Rico B, Xu B, Reichardt LF (2002) TrkB receptor signaling is required for establishment of GABAergic synapses in the cerebellum. Nat Neurosci 5: 225-233. doi:10.1038/nn808

Rocamora N, García-Ladona FJ, Palacios JM, Mengod G (1993) Differential expression of brain-derived neurotrophic factor, neurotrophin-3, and low-affinity nerve growth factor receptor during the postnatal development of the rat cerebellar system. Mol Brain Res 17: 1-8. doi:10.1016/0169-328x(93)90065-w

Schwartz PM, Borghesani PR, Levy RL, Pomeroy SL, Segal RA (1997) Abnormal cerebellar development and foliation in $B D N F^{/-}$mice reveals a role for neurotrophins in CNS patterning. Neuron 19: 269-281. doi:10.1016/ s0896-6273(00)80938-1

Sherrard RM, Bower AJ (2002) Climbing fiber development: Do neurotrophins have a part to play? Cerebellum 1: 265-275. doi:10.1080/ 147342202320883579

Sherrard RM, Dixon KJ, Bakouche J, Rodger J, Lemaigre-Dubreuil Y, Mariani J (2009) Differential expression of TrkB isoforms switches climbing fiber-Purkinje cell synaptogenesis to selective synapse elimination. Dev Neurobiol 69: 647-662. doi:10.1002/dneu.20730

Shimizu N, Itoh R, Hirono Y, Otera H, Ghaedi K, Tateishi K, Tamura S, Okumoto K, Harano T, Mukai S, et al (1999) The peroxin Pex14p: cDNA cloning by functional complementation on a Chinese hamster ovary cell mutant, characterization, and functional analysis. I Biol Chem 274 12593-12604. doi:10.1074/jbc.274.18.12593

Shimozawa N, Tsukamoto T, Nagase T, Takemoto Y, Koyama N, Suzuki Y, Komori M, Osumi T, Jeannette G, Wanders RJA, et al (2004) Identification of a new complementation group of the peroxisome biogenesis disorders and PEX14 as the mutated gene. Hum Mutat 23: 552-558. doi:10.1002/humu.20032

Shimozawa N, Tsukamoto T, Suzuki Y, Orii T, Shirayoshi Y, Mori T, Fujiki Y (1992) A human gene responsible for Zellweger syndrome that affects peroxisome assembly. Science 255: 1132-1134. doi:10.1126/ science.1546315
Steinberg SJ, Dodt G, Raymond GV, Braverman NE, Moser AB, Moser HW (2006) Peroxisome biogenesis disorders. Biochim Biophys Acta-Mol Cell Res 1763: 1733-1748. doi:10.1016/j.bbamcr.2006.09.010

Sugihara I (2005) Microzonal projection and climbing fiber remodeling in single olivocerebellar axons of newborn rats at postnatal days 4-7. J Comp Neurol 487: 93-106. doi:10.1002/cne.20531

Tamura S, Matsumoto N, Imamura A, Shimozawa N, Suzuki Y, Kondo N, Fujiki Y (2001) Phenotype-genotype relationships in peroxisome biogenesis disorders of PEX1-defective complementation group 1 are defined by Pex1p-Pex6p interaction. Biochem J 357: 417-426. doi:10.1042/02646021:3570417

Torvik A, Torp S, Kase BF, Ek J, Skjeldal O, Stokke O (1988) Infantile Refsum's disease: A generalized peroxisomal disorder. Case report with postmortem examination. J Neurol Sci 85: 39-53. doi:10.1016/0022-510x (88)90034-2

Tsukamoto T, Yokota S, Fujiki Y (1990) Isolation and characterization of Chinese hamster ovary cell mutants defective in assembly of peroxisomes. J Cell Biol 110: 651-660. doi:10.1083/jcb.110.3.651

Ueno M, Hayano Y, Nakagawa H, Yamashita T (2012) Intraspinal rewiring of the corticospinal tract requires target-derived brain-derived neurotrophic factor and compensates lost function after brain injury. Brain 135: 1253-1267. doi:10.1093/brain/aws053

Volpe JJ, Adams RD (1972) Cerebro-hepato-renal syndrome of Zellweger: An inherited disorder of neuronal migration. Acta Neuropathol 20: 175-198. doi:10.1007/bf00686900

Wanders RJA, Waterham HR (2006) Biochemistry of mammalian peroxisomes revisited. Annu Rev Biochem 75: 295-332. doi:10.1146/annurev. biochem.74.082803.133329

Watanabe M, Kano M (2011) Climbing fiber synapse elimination in cerebellar Purkinje cells. Eur J Neurosci 34: 1697-1710. doi:10.1111/j.14609568.2011.07894.x

Waterham HR, Ebberink MS (2012) Genetics and molecular basis of human peroxisome biogenesis disorders. Biochim Biophys Acta-Mol Basis Dis 1822: 1430-1441. doi:10.1016/j.bbadis.2012.04.006

Weller S, Gould SJ, Valle D (2003) Peroxisome biogenesis disorders. Annu Rev Genomics Hum Genet 4: 165-211. doi:10.1146/annurev. genom.4.070802.110424

Yacoubian TA, Lo DC (2000) Truncated and full-length TrkB receptors regulate distinct modes of dendritic growth. Nat Neurosci 3: 342-349. doi:10.1038/73911

Yoshii A, Constantine-Paton M (2010) Postsynaptic BDNF-TrkB signaling in synapse maturation, plasticity, and disease. Dev Neurobiol 70: 304-322. doi:10.1002/dneu.20765

Zhou P, Porcionatto M, Pilapil M, Chen Y, Choi Y, Tolias KF, Bikoff JB, Hong EJ Greenberg ME, Segal RA (2007) Polarized signaling endosomes coordinate BDNF-induced chemotaxis of cerebellar precursors. Neuron 55: 53-68. doi:10.1016/j.neuron.2007.05.030

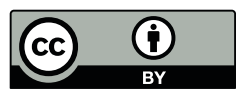

License: This article is available under a Creative Commons License (Attribution 4.0 International, as described at https://creativecommons.org/ licenses/by/4.0/). 